\title{
Constructing M\&A valuation: how do merger evaluation methods differ as uncertainty and controversy vary?
}

\author{
Hyoung-Goo Kang ${ }^{1}$, Wonseok Woo ${ }^{2}$, Richard M. Burton ${ }^{3}$ and Will Mitchell ${ }^{4^{*}}$
}

\author{
* Correspondence: \\ william.mitchell@rotman.utoronto.ca \\ ${ }^{4}$ Strategic Management, Rotman \\ School of Management, Toronto, \\ Canada \\ Full list of author information is \\ available at the end of the article
}

\begin{abstract}
We investigate the idea that firms' choices of M\&A evaluation methods are influenced by two socio-political factors that arise in the behavioral theory of the firm-uncertainty and controversy. In doing so, we investigate boundary conditions between arguments that expect firms to use financial analysis such as net present value as the primary tool and arguments that emphasize different forms of sociopolitical processes, often supplemented by subsequent financial analysis. We undertake exploratory qualitative analysis of multiple cases at a Korean chaebol, complemented by interviews with global deal-makers. The analysis highlights four approaches to M\&A evaluation that vary with combinations of uncertainty and controversy: desktop valuation based on financial analysis, capability design using scenario-planning and goal-setting techniques, issue lists that identify conflicting goals, and storytelling methods that attempt to articulate compelling logics for a deal. The results suggest that M\&A values are sometimes endogenously created as a result of the method that firms use to evaluate a deal. The work addresses and links two audiences: First, M\&A scholars who often do not engage with the idea of sociopolitical processes but are open to the idea that there are important boundary conditions to the frameworks that are relevant when one does not do so. Second, scholars who do regularly engage with the idea of socio-political processes and are intrigued with determining how social constructs such as uncertainty and controversy will shape particular types of decisions.
\end{abstract}

Keywords: Mergers and acquisitions, Valuation, Uncertainty, Controversy, Capital budgeting

\section{Introduction}

Research in finance, strategy, and management demonstrates that firms use multiple combinations and sequences of quantitative and qualitative methods to evaluate business acquisitions (Mellen and Evans 2010). Some approaches emphasize identifying the underlying financial value of a deal (Brealey et al. 2005; Ross et al. 2009) and then use qualitative assessment to reinforce the value in what Trice et al. (1969: 2) refer to as "organizational ceremonials." By contrast, other approaches suggest that socio-political context of a deal shapes initial construction of the qualitative value of strategic options followed by financial methods that justify or clarify the decisions (Trautwein 1990; Gaughan 2002; Koller et al. 2010; Bower 1970; Narayanan 1985; Maritan 2001; Graham 
and Harvey 2002; Graham et al. 2005); in this approach, financial valuations serve as the organizational ceremonials. Although we recognize that alternative sequences of qualitative and quantitative assessment exist, there are substantial gaps in our understanding of the characteristics of different methods as well as what factors influence the choices (Bower 2001; Christensen et al. 2011). This paper investigates two sociopolitical factors that arise in the behavioral theory of the firm (Cyert and March 1963) - uncertainty and controversy - and seeks to determine how the types of M\&A evaluation methods that firms use vary with different combinations of the sociopolitical factors.

We emphasize uncertainty and controversy based on suggestions that the concepts will be relevant for the socio-political context of deal making, such as M\&A evaluation. Bower (1970: 314), in particular, highlights these socio-political factors in capital budgeting activities, noting that, "At least two kinds of problems exist" in attempting to undertake financial decision-making, including uncertainty and what Bower refers to as controversialism (in our terms, controversy). Uncertainty in the form that we focus on arises when decision-makers cannot specify reliable statistical parameter distributions, such as mean and variance, which would help estimate the value of a decision (Knight 1921; Boudreaux and Holcombe 1989; Epstein 2001); this is sometimes referred to as Knightian uncertainty or as ambiguity. ${ }^{1}$ Knightian uncertainty differs from risk, for which a reliable distribution can be described. In parallel, controversy arises when there are at least two strong coalitions with competing goals (Weick 1979; Coff 1999; Burton et al. 2015). Although these two socio-political factors may partly operate at the same time, uncertainty and controversy have sufficient independence for separate examination (we discuss potential multicollinearity when addressing empirical issues in Stage 1 of the research design). Other factors also are likely to influence choice of evaluation methods, such as deal importance, firm size, and decision-maker experience, but uncertainty and controversy offer an empirically parsimonious and conceptually credible framing for the argument and analysis.

By examining the impact of uncertainty and controversy, we begin to unpack different aspects of Bower's notion of socio-political processes in a way that helps investigate M\&A evaluation. Acquisitions reflect substantial variation in uncertainty and social complexity (Cartwright et al. 1992; Cartwright and Cooper 1993). Investigating these two factors offers a starting point for clarifying how firms combine qualitative and quantitative M\&A evaluation methods in different contexts.

We use ten semi-structured case studies to explore how variation in uncertainty and controversy influence choices of M\&A evaluation methods. The cases include interviews and archival data regarding potential acquisition targets at a Korean chaebol during the 2000s, together with supplemental interviews with M\&A financial executives. Our qualitative empirical approach specifies framing concepts followed by triangulation plus within- and cross-case analysis to identify emergent concepts (Strauss and Corbin 1990; Eisenhardt 1989).

The work contributes to studies of acquisitions by identifying alternative M\&A evaluation methods and investigating boundary conditions in different explanations for choices of the methods. In doing so, we highlight differences in the sequences of financial and qualitative methods, address the importance of socio-political processes in deal valuation, and discuss the potentially endogenous nature of deal value. The results highlight relevant 
differences concerning who leads the evaluation process, in terms of both functional skill sets and use of external advisors to assist with deal evaluation.

Our research proceeded in three stages. In Stage 1 (identify independent variables), we identified multiple potential M\&A targets within the chaebol and selected cases that reflected combinations of high and low states of uncertainty and controversy, based on information from a series of initial interviews. That is, in order to avoid sampling on the dependent variable (valuation methods), we sampled in terms of the independent variables (uncertainty and controversy) that we wanted to investigate in terms of how they influence choices of valuation methods. In Stage 2 (characterize dependent variable), we assessed the approaches that the chaebol used to evaluate each potential M\&A deal. In Stage 3 (matching independent and dependent variables), we assess whether the evaluation methods tended to vary systematically across the combinations of uncertainty and controversy.

In this design, the unit of analysis is a deal, the independent variables are uncertainty and controversy (assessed in Stage 1), and the dependent variables (examined in Stage 2) are the evaluation methods the group used for deals with different combinations of uncertainty and controversy (matched in Stage 3). When we interpret the results, the types of evaluation methods that we identify arise as ex post categories, rather than preceding the analysis. Before explaining Stage 1, 2, and 3, the next section discusses the background of this paper.

\section{Background}

\section{Gaps in understanding about M\&A evaluation methods}

M\&As are critically important to corporate strategy and performance throughout the world (Capron 1999; Agrawal and Jaffe 2000). M\&A evaluation commonly involves combinations and sequences of quantitative and qualitative assessment. The most basic approach is financial assessment of whether two firms are more valuable jointly than separately, after estimating discounted cash flows and exposure to systematic risks (Brealey et al. 2005; Ross et al. 2009). In other cases, though, M\&A evaluation reflects socio-political factors that are not included in straightforward financial valuation models (e.g., Trautwein 1990; Haspeslagh and Jemison 1991; Capron et al. 1998; Bower 2001). Our goal is to find points of convergence and difference among financial and socio-political perspectives on M\&A evaluation methods, in order to identify a more general understanding of the types of M\&A evaluation tools that firms use and when particular tools are most common. We focus on uncertainty and controversy as factors that will shape abilities to estimate joint versus separate values (Gaughan 2002; Koller et al. 2010; Uhlaner and West 2011).

\section{Orienting proposition}

We begin with an orienting proposition that guided our qualitative empirical research. While theory about the choice of different types of M\&A evaluation methods is not strong enough to support detailed hypotheses, capital budgeting and behavioral theory studies offer sufficient guidance to identify framing concepts for investigating the phenomenon. This approach follows the tradition of Strauss and Corbin (1990), which suggests that it is appropriate to begin a project with a tentative set of expectations 
while leaving room for new ideas to emerge when there is enough conceptual background that fully inductive work is not necessary.

As we noted above, behavioral theory suggests that uncertainty and controversy shape major decisions. Uncertainty limits actors' ability to undertake focused financial analysis, turning attention instead to qualitative tools (e.g., Cyert and March 1963; Bower 1970; Eisenmann and Bower 2000; Bower and Gilbert 2005; Stirling 2010) such as scenario building (e.g., Nishimura and Ozaki 2006; Caballero and Krishnamurthy 2008). In parallel, controversy about major goals limits the utility of primary analysis, instead causing decision-makers to emphasize negotiation and building coalitions to support desired objectives (e.g., Giddens 1979, 1984; Weick 1979; Tjosvold \& Deborah 1980; Tjosvold 1985; Eisenhardt and Zbaracki 1992; Wall and Callister 1995; Nutt 1998; Holmstrom and Kaplan 2001; Kaplan 2008). These two concepts are likely to shape firms' choice of M\&A evaluation methods, although it is not immediately clear what form the evaluation methods will take. Appendix 1 outlines ideas from relevant strategy and organizational literatures about how uncertainty and controversy are relevant for studying M\&As.

We focus on uncertainty and controversy as general concepts. ${ }^{2}$ Clearly, one could elaborate on each concept. Within the definition of uncertainty as an actor's inability to specify a reliable distribution, other aspects of uncertainty can reflect elements such as complexity, volatility, unknowable versus unfamiliar, differences in ability to parameterize across actors, and differences in understanding of the elements of uncertainty (Knight 1921; Keynes 1921; Boudreaux and Holcombe 1989; Gilboa and Schmeidler 1989). Several scholars argue that firms frequently attempt to avoid uncertainty (Cyert and March 1963; Schmeidler 1989). Within the general definition of controversy as the presence of competing goals among coalitions, meanwhile, controversy may involve differences in ranges of stakeholders and potential compatibility or incompatibility of goals among executives, variations in power, depths of beliefs, and differences in understanding of the relevant dimensions (Tjosvold and Deborah 1980; Tjosvold 1985; Eisenhardt and Zbaracki 1992). Related concepts include controversy in Hobbes (1651), Coase (1946), and Rawls (1971); conflict in Cyert and March (1963); controversialism in Bower (1970); alignment of interests between principals and agents (Jensen and Meckling 1976; Holmstrom and Tirole 1989); opportunism, information impact, and information asymmetry (Akerlof 1970; Williamson 1975); and organizational politics (Cyert and March 1963; Pettigrew 1973). Such multi-dimensionality of the concepts of uncertainty and controversy is beyond our empirical range and, importantly, is often beyond the scope of the factors that decision-makers address in practice.

Our orienting proposition is that as uncertainty and/or controversy increase, firms will increasingly evaluate potential deals via qualitative methods. The capital budgeting literature highlights both financial and qualitative decision-making processes. Financially driven approaches such as NPV will be most feasible when uncertainty and controversy are low: in those conditions, it is possible to identify meaningful parameters for financial models and settle on focal goals that the financial models can assess. By contrast, financial models are more difficult to use as primary decision-making tools when uncertainty and/ or controversy increase. Uncertainty means that distributions for the variables in financial models will be unreliable; e.g., actors cannot specify meaningful discount rates for measures such as NPV. Controversy means that it becomes increasingly difficult to determine 
benchmarks by which to assess financial output or even to use financial models. We will use the orienting proposition as a base from which to explore the types of methodologies that arise as uncertainty and controversy vary.

\section{Empirical context: Korean chaebol}

For the empirical exploration, we identified a Korean chaebol that evaluated multiple potential M\&A targets during the 2000s. From 2010 through 2012, we started from personal networks to reach executives at the chaebol (two authors have investment banking, consulting, and chaebol experience), which helped develop a rich understanding of potential deals and the evaluation methods the firm used for individual deals. We study multiple cases of M\&A within a single chaebol in order to control firm-level variation of factors such as culture and governance, so that we can focus on the effects of varying uncertainty and controversy. Additional interviews with investment bankers, lawyers, and accountants with extensive M\&A experience at the focal chaebol and across global markets supplemented the cases. The case study design derives from the qualitative procedures for grounded theory suggested in Strauss and Corbin (1990) and Bettis et al. (2015). In total, the interviews and data acquisition took about 3 years to carry out.

Chaebols are relevant organizations in which to study decision-making because of their size, scope, and global influence (Chang 2003); Appendix 2 provides more details about chaebols. Our subject chaebol has a strongly shared culture among its employees and businesses. The chaebol has a central think tank (which is common among major chaebols), plus long-standing systems in charge of managing shared culture across subsidiaries. The shared culture helps minimize affiliate-specific effects; indeed, a simple ex ante expectation would be that members of the chaebol would use the same evaluation techniques for all potential deals.

\section{Stage 1: identifying variation in uncertainty and controversy (independent variables)}

Case selection had three steps: (1) identifying respondents, (2) initial assessment of uncertainty and controversy, and (3) iterating the process to converge on clear-cut assessments. First, we identified executives who were aware of the deals that the chaebol had considered from 2000 to 2012. We began with personal contacts and then expanded to executives the first contacts suggested.

Second, we sought to identify cases that varied in uncertainty and controversy. We determined uncertainty based on how reliably the acquiring firm could assess the nature of the target's capabilities as well as the opportunities in the market for which the capabilities would be used (i.e., the extent to which the firm could or could not assign a reliable probability distribution to the value of the deal). In turn, we determined the extent of controversy based on what the respondents told us about the degree of consensus within the buyer about the value of the potential target's capabilities and about how the buyer might use them if it were to complete the deal. In most interviews, we explained the definition of uncertainty and controversy, though in nine interviews, we first asked the respondents to tell us about the context in which consideration of the acquisition took place to help ensure that we were not inappropriately seeding the concepts. In cases where we defined uncertainty and controversy for the respondents, 
they differentiated between high and low states. In the cases where we did not explicitly define the concepts in the beginning, we judged the high and low states based on their description of the deal. From the interviews, we identified cases with combinations of high and low states of uncertainty and controversy, based on the descriptions that the interviews provided.

Table 1 summarizes the cases. Column 1 lists the cases, while columns $2 \mathrm{a}$ and $2 \mathrm{~b}$ summarize uncertainty and controversy status based on the interviews in Stage 1. Columns $3 \mathrm{a}$ and $3 \mathrm{~b}$ summarize the evaluation methods (we discuss the evaluation method labels in column $3 \mathrm{~b}$ when we describe Stage 2 below.)

The ten targets, which were evaluated by five different affiliates of the chaebol, include a mix of opportunities: Portal (web portal with an established search engine), SmallEnergy (domestic utility company), BigMedia (chain of movie theaters), upposeBigEnergy (foreign utility), Chip (global semiconductor player), Apparel (small fashion company), SNS (early social network service), Card (domestic credit card business), BigMobile (US wireless operator), and SmallMedia (media content specialist). Together, the cases provide a strong base for studying M\&A evaluation methods. The cases provide relevant combinations of uncertainty and controversy. They also provide enough information to permit a rich study that assesses the core concepts, while allowing ideas to emerge from the investigation. Information about evaluation processes-the dependent variable-emerged from the interviews during Stage 2 of the research.

\section{Independent variables: assessing uncertainty and controversy}

The following discussion addresses how we measured the independent variables, that is, the extent of uncertainty and controversy for each case. This is a form of withincase analysis (Eisenhardt 1989). We triangulated the analysis with multiple interviewees and archival documents. We determined the extent of uncertainty based on how reliably the acquiring firm believed it could assess the nature of the target's capabilities as well as the opportunities in the market for which the capabilities would be used (i.e., the extent to which the firm could or could not assign a probability distribution to the value of the deal). In turn, we determined the extent of controversy based on what the respondents told us about the degree of consensus within the buyer about the value of the potential target's capabilities and about how the buyer might use them if it were to complete the deal.

\section{Low uncertainty and low controversy}

Several quotations from the interviews illustrate that uncertainty and controversy were low in Portal and SmallEnergy. The managers in charge of the Portal deal assessed uncertainty in terms of "whether it is easy to quantify the combined value of the target and the deal." They concluded that uncertainty was low because "page views and user size inform the value of the target and synergy." The target's main capability (a search engine) did not overlap with the buyer's capabilities, so that "simply adding the users in the target and the buyer" could approximate the number of users and value of the combined entity. The managers measured the extent of controversy with how much consensus the buyer had about the value of complementary capabilities in the target. Managers within the buyer agreed that "the target had a strong search engine." In contrast, the buyer firm did not have a strong search engine, which the buyer's executives 


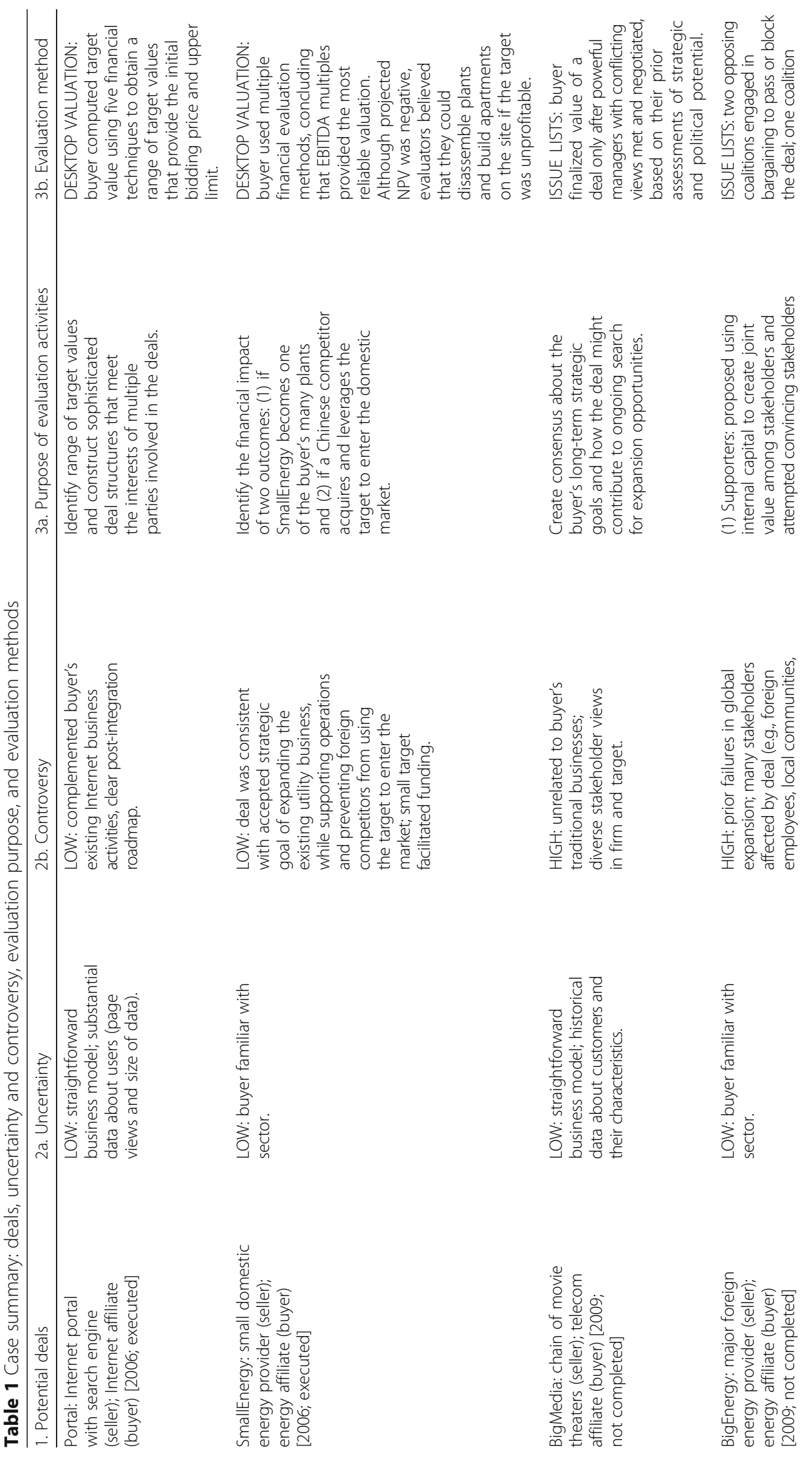




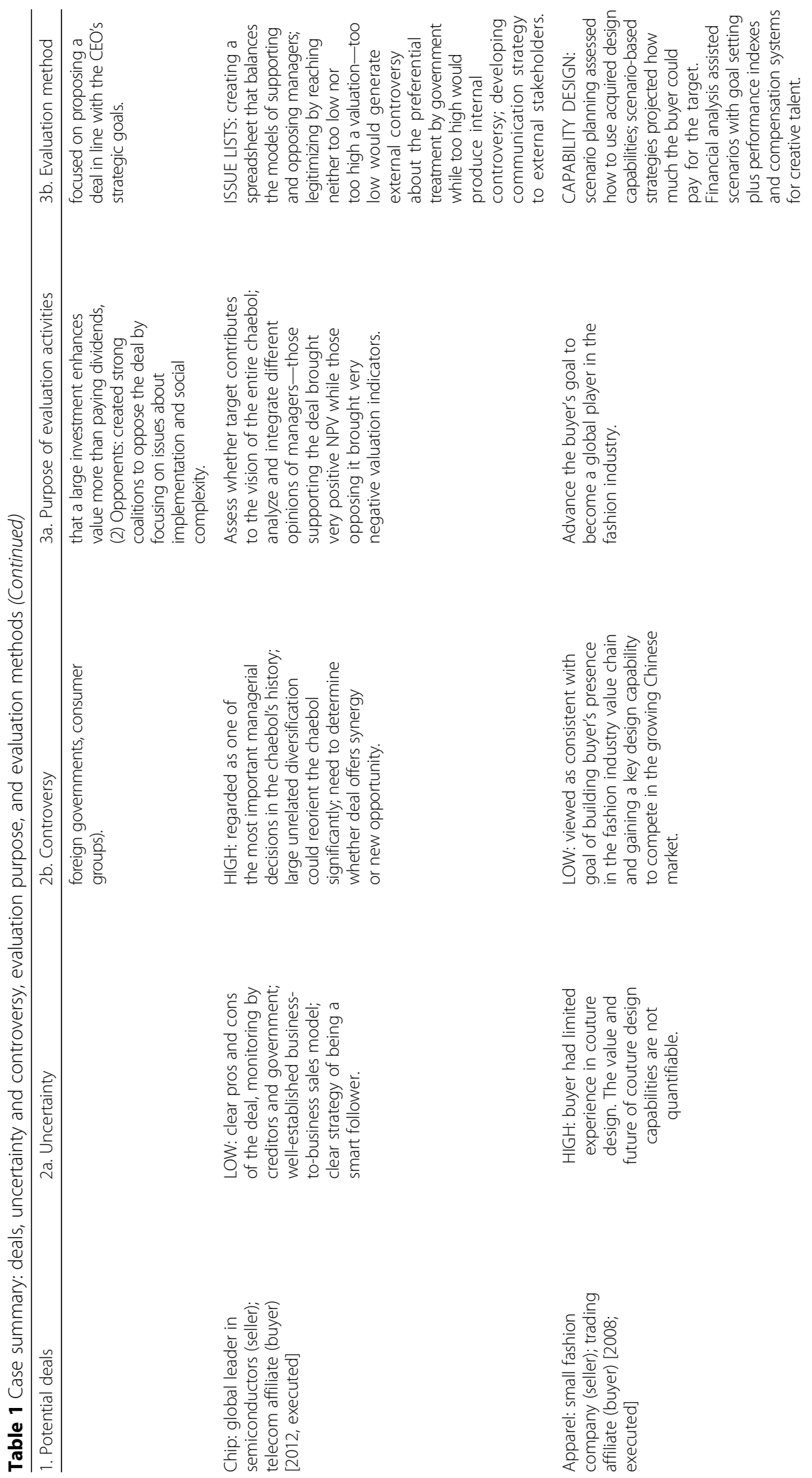




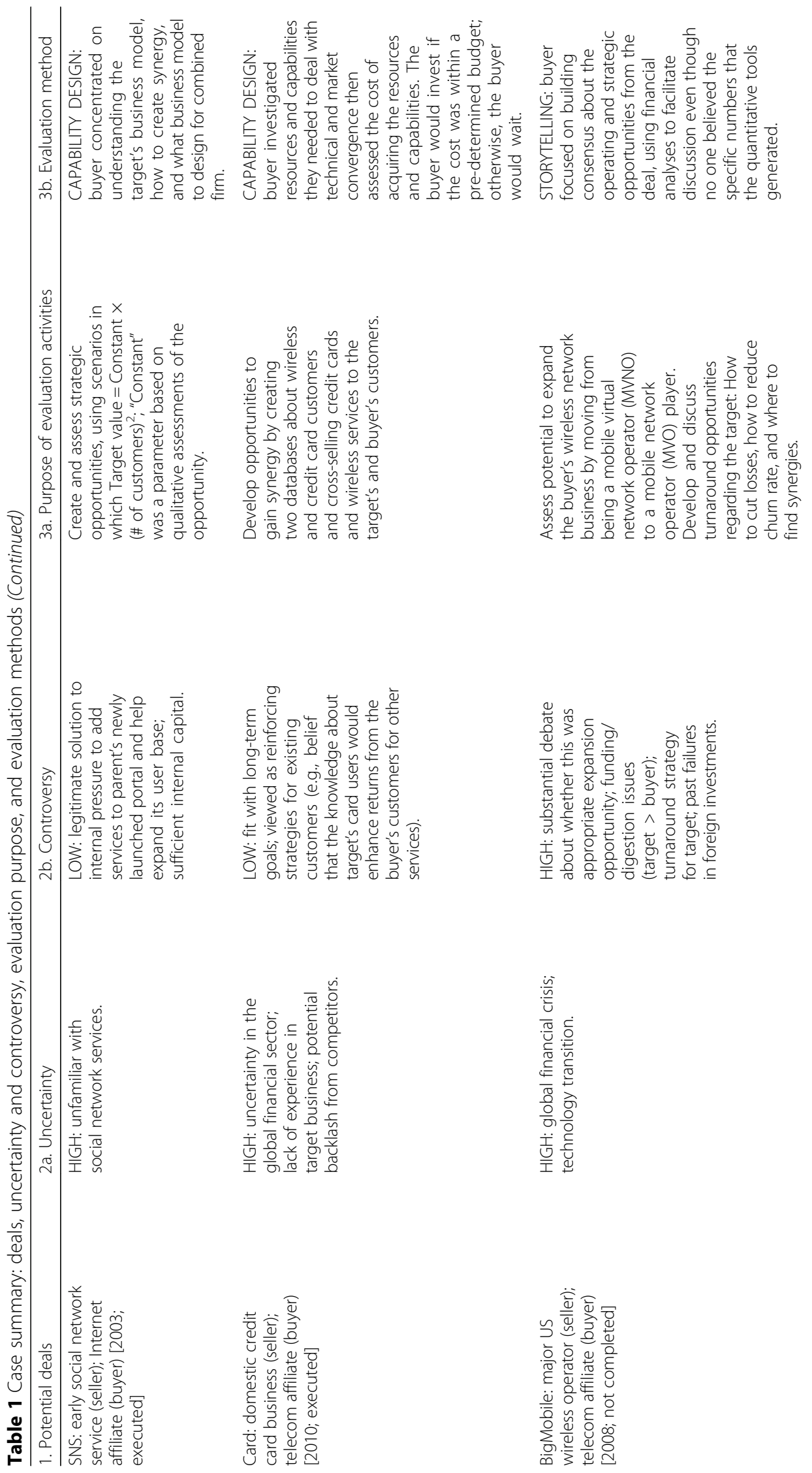




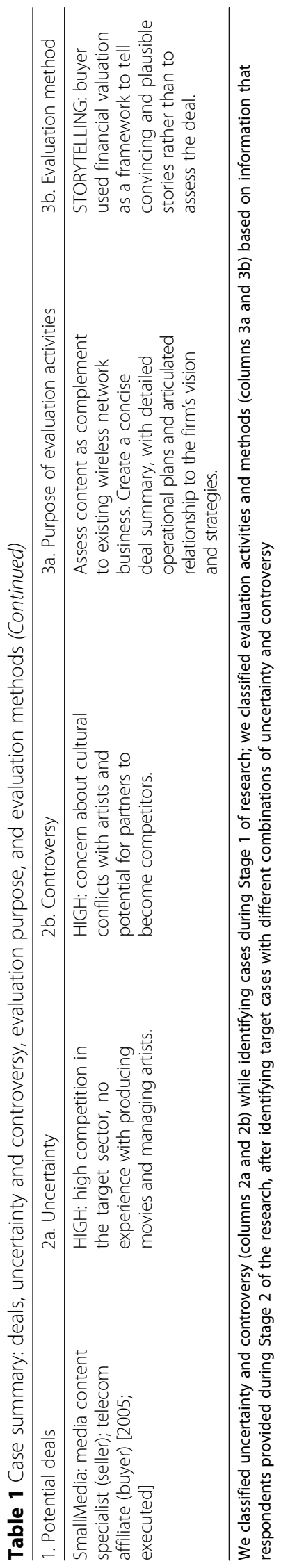


believed was "essential in becoming a market leader." Thus, all key managers at the buyer welcomed the deal.

From the interviews about Portal:

Low uncertainty: "We combined the number of the target's and our page views for valuation. They did not overlap much because users use two sites for different purposes." "We had a large number of log-in users, while the target's search engine had many visitors. The combined business model is very easy to conceptualize. The value proposition of our new portal was straightforward."

Low controversy: "We had tried to develop our own search engine in vain. ... We needed that capability to make our portal successful. ... The target had a good search engine." "We had strong communities and social networks. A search engine was the only missing part." "The target's search engine would allow us to enter the market for search ads." "Less than $30 \%$ of our log-in users had used our search engine before the merger. ... Our log-in users had created a lot of contents, but could not access them through search engine." "Neither we nor the target were market leaders. We needed to work together to overtake the market leader."

Interviewees for the SmallEnergy deal assessed uncertainty in terms of "familiarity of the business." The buyer and the target were in the same sector, but, although the deal was important to the affiliate because it would help advance the top management teams' strategy, the target was smaller than the buyer. As such, the perceived uncertainty was low. Controversy was low because the deal would be easy to finance and because there was consensus about the strategic value of the deal. The interviewees believed the deal was necessary "in order to become a global player" in line with the firm's strategic goals and "to prevent foreign competitors from using the target as a stepping-stone to entering the domestic market." Interestingly, despite the pre-deal consensus, an interviewer now regrets the deal, telling us that "we should not have acquired [SmallEnergy]" owing to difficulties in generating value from its resources.

From the interviews about SmallEnergy:

Low uncertainty: "The target was a small company and in the same sector as ours." "The target was just like one of our plants. There was no uncertainty." "It was likely that we would lose some money with the target, but the target was clearly at strategic position." "There were many ways to convince the government about anti-trust dispute in the deal."

Low controversy: "Unless one of our domestic players buys the target, foreign firms will buy it and become a competitor. Our firm is the market leader, so we had to buy it." "We expected the deal would consolidate our leadership in the domestic market and position us as a global player in line with our vision." "Being a major player in the oil industry, we could facilitate our many activities like financing, alliance, and bargaining." "We would leverage the target to enter Chinese market as we planned." "The target had made too much noise in domestic market with disruptive marketing activities. The acquisition would stabilize the domestic market and marketing practices." "The target is close to the biggest domestic market; thus, after the acquisition, we would not have to transport our products from remote plants."

High uncertainty and low controversy

Several quotations illustrate the combination of high uncertainty and low controversy for the Apparel, Card, and SNS cases. The interviewees for the Apparel deal assessed 
uncertainty in terms of experience and cultural differences. The buyer had little experience in design, but the target had strong capabilities. This made it difficult to assess the value of the deal quantitatively. Cultural fit was another concern: "We are a big firm with collective culture, while the target consisted of designers, artists, and people with a small-firm mindset." The interviewees assessed controversy in terms of the perception that value-chain complementarities existed. There was an internal consensus that "we should develop an in-house design capability to enter the Chinese market and became a prominent fashion house. The target possessed the needed design capability." Therefore, the deal produced little controversy.

From the interviews about Apparel:

High uncertainty: "We acquired the target in order to obtain their design capabilities. It is almost impossible to conduct valuation for its design capabilities quantitatively." "We knew fashion design was full of uncertainties. So, we neither modeled nor estimated future cash flows." "We were in a hurry to complete the deal in 25 days. So, we did not have the time to do a detailed financial analysis or to prepare potential uncertainties about cultural issues with the target's designers." "Our goal was to enter global fashion markets, but the financial crisis added significant uncertainties." "Designers' emotion and feeling mattered to accomplish a successful integration." "People were less confident with acquiring a firm in a different sector. Many doubted whether we could handle the deal and integration."

Low controversy: "Top managers in our holding company joined the deal process and sponsored it from the beginning." "Everyone fully knew why we needed the design capabilities of the target." "There was no controversy in and out of our firm. Everyone cheered the deal." "We want to become a brand player like LVMH or Chanel. Design capabilities, especially for couture, play an essential part in the value chain to accomplish our vision." "We did not have design capabilities for globalization, while the target lacked resources to expand its design capabilities into the global market. We were a perfect match." "Few people objected to the deal, but many worried what to do after the integration." "Globalization in fashion business requires design capabilities."

The interviewees for the Card deal assessed uncertainty in terms of global uncertainty in the financial sector, lack of experience, and concern about backlash from competitors. They assessed controversy in terms of "fit with traditional and long-term goals and with behaviors of existing customers" (i.e., whether the knowledge about the target's card users would enhance returns from the buyer's customers). Most of all, the urgency to increase average revenue per user (ARPU) in the mature domestic wireless market pushed the buyer to brainstorm for new services, such as combining mobile and financial services (cross selling). This meant high uncertainty and low controversy within the firm.

From the interviews about Card:

High uncertainty: "The target did not have large credit card users. We needed to evaluate our capabilities of increasing the card users." "We had tried mobile finance services before, but failed. To create synergy with the target, we should introduce new and even untested services." "Our competitors were making the same effort. Handset makers were building alliance with other credit card firms. Banks were making alliance with our competitors to lead the mobile finance services. The competitive dynamics around the convergence of wireless and financial services are still complex." "Entering 
the financial sector could increase the uncertainty of all Chaebol subsidiaries, especially when financial crisis emerged."

Low controversy: "The more people use smart phones, the more the financial functions matter to mobile services. We needed to move first." "As the wireless market became saturated, we needed to find a new source of revenue to increase ARPU. We needed out-of-the-box thinking." "We had tried to enter the credit card business for a long time." "Credit service would lower churn rates." "Given our marketing costs, the deal was not a big expense." "Our database on mobile and membership card users will create synergies with credit card users."

The SNS interviewees regarded uncertainty as high because "the target's business model was innovative and Internet users were unpredictable." They regarded controversy as low because top managers at the holding company all saw innovation at the target. "We had invested many resources to find innovative services and to become a leader quickly." While the target's business model was difficult to comprehend, there was agreement that this might have large potential for the buyer's future; interestingly, controversy was low because uncertainty was high. The target also had a large number of users that stakeholders at the buyer needed.

From the interviews about SNS:

High uncertainty: "Suppose you saw Facebook 10 years ago. Do you think you would have understood the business model?" "It is one of the first serious social networking services. Few could comprehend what we could do with it and how to generate cash flow." "Tastes of Internet users are unpredictable anyway."

Low controversy: "We desperately needed an engine for growth." "Although it was difficult to understand the business model, we felt there might be something innovative. The uncertainty in the business model actually minimized controversy. Experts and visionaries' opinions mattered more." "We needed an investment opportunity in which we could spend our resources. Abundant internal resource must have driven valuation process." "We had pressure from the top to deliver something." "We entered the portal market late, so we had to acquire an established player like SNS." "They had many online communities while we had none." "It cost just seven million dollars to acquire it." "The target's social networking services and our existing portal may conflict, but could be complementary as well."

\section{Low uncertainty and high controversy}

Several quotations from our cases illustrate the combination of high uncertainty and low controversy in BigMedia, BigEnergy, and Chip. The interviewees about BigMedia assessed uncertainty in terms of industry dynamics. The target operated a movie theater chain. The interviewees regarded the sector as "saturated and well known." The market share of competing firms had remained constant for several years. Interviewees assessed controversy in terms of "how the business fit our vision, what disagreements we have then, which strategies to take in order to use the target to enter the Chinese market, and how stock analysts might react."

From the interviews about BigMedia:

Low uncertainty: "The movie theater sector was safe, boring, and saturated." "It was almost a traditional business." "The business model is straightforward unless we extend the target significantly for global expansion." "The business to produce movie contents can be full of uncertainties, but distribution is not." 
High controversy: "There was not much uncertainty, which may imply fewer opportunities. That was the cause of much controversy in the deal." "The sector was mature, not good for our growth strategy." "Movie chains can be valuable in entering the Chinese market, but I wonder whether they are in line with our traditional business." "Post-merger strategy was unrealistic to the managers in charge of implementation." "The vision seemed convincing, but it would be very hard to implement." "The target was only a minor player in the sector. Its market share was shrinking. It required business-grouplevel marketing coordination to turn around the target after the deal." "Stock analysts were highly skeptical about the deal. Our stock price in fact rose after our bid failed." "We should not propose a deal without considering execution in great detail, although some would disagree." "The stakeholders of the target were very heterogeneous with different interests." "Entertainment is not in our path." "It was unrealistic to use the target to enter a foreign market. Would foreign competitors sit idly?" "Our team would have to take over the business if the deal succeeded. The plan would simply put us on the brink. The deal may be profitable, but we should consider the implementation and operation parts more seriously. Deal makers and we have very different incentives." "Our conservative culture was at odds with many merger deals." "Subgroups in our traditional businesses did not like entering this type of new area. They argued that such deals would reduce our capabilities in key sectors."

Interviewees about BigEnergy assessed uncertainty in terms of whether the buyer had experience in the target sector. The interviewees perceived uncertainty as low because the target and the buyer were in the same sector. Interestingly, the interviewees also assessed controversy based on their past experience. The buyer had experienced little success in global markets, which made the deal controversial in the organization. In addition, the target had many stakeholders, including foreign employees, local communities, foreign governments, and other consumer groups, which added further layers of controversies to the deal.

From the interviews about BigEnergy:

Low uncertainty: "We and the target were in the same sector." "It was easy and familiar for us to valuate oil refinery firms." "We knew that the boom of oil business would be short. Refinery business will be difficult until 2015 or 2020." "The technology for refinery is not special." "There were not many rooms for synergy. It would be certainly difficult to come up with an innovation to make the target suddenly more productive. These commodity products did not allow visible synergy. The target had few employees either, so the benefit from restructuring would be minimal."

High controversy: "Most of our attempts to expand globally have failed until now." "It was unclear how to address the challenges of managing foreign employees, community, local government, and other stakeholders in the deal." "Our CEO made a very judicious decision in the middle of heated debates and conflicting views, by balancing different opinions and fostering negotiations, even though he had preferred entering the North American market." "Some managers chase deals without worrying about post-merger integration. Some managers are very cautious on deals because they have to implement them. People's different incentives generate controversies as this deal demonstrated." "While top managers and their aides are eager to find a deal, operations managers are very cautious." "Operations managers and minor shareholders are conservative about big deals, but top managers have grand ambitions to become a global 
player by acquiring North American players." "A huge amount of internal capital increased the level of controversy about how to use the internal capital: big projects vs. payout." "Deal brokers such as M\&A boutiques were good at reading the minds of top managers. However, many suspect that deal brokers tend to propose deals for their own interest only."

Interviewees about Chip assessed uncertainty in terms of the target's future strategy and the characteristics of global semiconductor industry. The interviewees perceived uncertainty as low because being a smart follower is the clear strategy for the target; the semiconductor sector is business-to-business, so that marketing and sales are less subject to the whim of high tech retail consumers, and the monitoring and support from external stakeholders such as creditors and the government can reduce uncertainties. On the other hand, controversy is high. The deal was regarded as "one of the most significant in the history of our group," such that the deal could strongly influence the future of the chaebol. There were internal controversies about whether the deal was to create synergy or to find new growth opportunities. There were external controversies about whether the deal was a special favor of the government to the chaebol and whether premiums would reflect the interests of both internal and external stakeholders.

From the interviews about Chip:

Low uncertainty: "The target has done well even without financial and technological capabilities. They can continue what they have done. In addition, with our resources, it can succeed further." "The target can simply follow the strategy of Samsung, the leader of the semiconductor sector." "Being a smart follower is simple compared with other strategies." "The semiconductor business is less uncertain than other high tech businesses such as smart phones. The former is business-to-business while the latter is for retail customers." "The subject had been in the M\&A market more than 10 years. We examined the subject and had prepared the deal for a very long time. We set up a team internally to research the subject and potential deal. We received a lot of external consulting and advice." "It is not a cross border deal."

High controversy: "Top managers had substantial differences of opinions. Such differences were discussed and addressed at the very high level of managers. The deal did not go through low-level processes to balance the differences." "While the deal has low uncertainty, it has high controversy. Low uncertainty implies clear pros and cons about the deal; that clarity generates controversy." "This is one of the most important deals in the history of our group. This can change our future significantly. We had substantial differences of opinions. This is not surprising." "This is serious unrelated diversification. The key issue was whether the subject would enhance the resource and capability of our entire business groups." "If the premium we pay is too low, people will regard this deal as the preferential treatment of government. If the premium is too high, internal objections will be stronger despite the will of top executives." "This deal will make us a global player suddenly. Does it correspond to our vision?" "We needed to determine whether the deal would generate synergy or find new growth opportunities."

High uncertainty and high controversy

Several quotations from our cases illustrate the combination of high uncertainty and low controversy for BigMobile and SmallMedia. The interviewees about BigMobile viewed uncertainty as high because the deal required an unfamiliar amount of large financing and included non-market factors. The interviewees were concerned with the 
ramifications of such large financing, how to structure the deal or syndicate composition, and how foreign governments would respond. The interviewees also considered controversy based on their past experience. Little experience of success in global markets made the deal controversial. In particular, a similar deal by the firm had recently failed, so that starting the new deal generated large controversy in the buyer. In addition, the interviewees assessed controversy based on the number of stakeholders in the target. Since the target had gone through a merger and was being integrated, its organizational culture and governance were complex. Foreign governments thought that the target was important in national security. There had been debates about whether the deal would present the best use of their resources and capabilities.

From the interviews about BigMobile:

High uncertainty: "We were not confident enough to manage the target after the deal." "There would be many uncertainties in raising such a large amount of funds." "Even if the deal had succeeded, we would have faced regulatory uncertainties because the target owned significant national infrastructure. We did not know how new administrations would change policy and how public opinions would change." "The deal was too large. I was not sure whether we had the capabilities to manage the integration process." "I do not believe we had the capabilities to structure the deal for our best interests." "The economy was about to downturn. There was significant macroeconomic uncertainty." "We did not know much about the culture and the industrial norm of the target."

High controversy: "We failed a greenfield strategy as a mobile virtual network operator (MVNO) recently. We sold the venture. Would it be wise to invest in the same market in order to acquire an MVNO player?" "Without any experience of success in global expansion, I was not sure whether we could convince people to agree on such a large investment." "The target is twice the size of our company. It would be very difficult to convince our shareholders and other stakeholders." "How could we convince the foreign government to allow us to buy the significant national infrastructure?" "The target was a complicated entity because it merged with its large competitor recently and operated two separate wireless networks." "The deal would consume our internal resources, which we could use more productively in other ways."

The interviewees about SmallMedia assessed uncertainty in terms of how familiar the buyer was with the target's culture, sector, prospect, and strategies. The target produced entertainment content, a sector that was "volatile and relied on several key people." A trend of industry convergence added further uncertainty. Moreover, the buyer had little experience in the sector. Thus, interviewees regarded uncertainty about the deal as high. The interviewees assessed controversy with "cultural fit, investment horizon, and governance" issues. Many people within the firm believed that the entertainment sector might not fit with the buyer's conservative culture and its impatience with long-term investment. Many people worried that it might be a bad idea to "allow much discretion to the existing management of the target" as the deal specified.

From the interviews about SmallMedia:

High uncertainty: "Entertainment is people business. It is uncertain how to value and manage key people." "It is uncertain how to find a new growth engine in the entertainment sector. I wish we identified growth factors through valuation in order to invest right away." "The target had not performed well. The target's future was very uncertain 
in the already uncertain entertainment sector." "It was almost impossible and meaningless to evaluate the uncertainties in contents and entertainment sector financially! That would require too many variables and assumptions." "The target could lead us to prepare the convergence of communication and broadcasting, the path of which was still uncertain." "How to build the capabilities of star management and production with the target was the most uncertain but important factor in the deal." "The target should become instrumental in our global strategies although we would develop a more detailed road map later."

High controversy: "Our telecom businesses tend to be conservative toward risks, which contrasted the target's business model and culture." "Investments in visual and audio contents required our patience. Long-term investment was required, and profit would remain low for a long time." "I was not sure whether the target could produce contents suitable for our mobile users. I was not sure whether it was our priority to become a media and entertainment company." "We had promised not to intervene with the management of the target, but such nonintervention might hamper building our capabilities, the very purpose of this deal." "We expected many conflicts and controversies during integration process between the target's and our people."

\section{Empirical issues in Stage 1}

\section{Combinations of uncertainty and controversy}

The four combinations of uncertainty and controversy reflect different mixes of beliefs about probability distributions. With a more fine-grained measurement of uncertainty and controversy (e.g., high, middle, low), we would have needed a substantially larger number of cases and interviews to carry out the research. Fortunately, we were able to identify cases that reflected clear differences in levels of high and low uncertainty and controversy.

We conducted at least two interviews per case. In total, we discussed 13 potential deals with 41 people. The face-to-face interviews occurred from March 2011 through July 2012. Less formal email and telephone interviews that complemented the face-toface interviews occurred during the following year.

We used three criteria to select target cases from the set of deals we discussed with respondents. (1) We selected a mix of cases with high and low uncertainty and controversy, based on the information from the first stage interviews. (2) We assessed the importance of a case to the chaebol based on discussions during the interviews; we wanted cases with sufficient financial value and/or extensive media attention to have substantive importance to the firm and receive substantial corporate attention. (3) We selected cases only when we could find reliable interviewees and could gain supplemental access to internal archival information about the deals.

We followed guidelines for semi-structured interviews (Huber and Power 1985; Yin 1985). We sent questions to our interviewees beforehand via e-mail and supplemented face-to-face interviews with phone and e-mail. In-person interviews in Korean lasted about 2 hours. Two thirds of the interviews occurred in the interviewees' office, while the others occurred in restaurants at the suggestion of interviewees. Two authors attended about one third of the interviews together; the other interviews were one-onone meetings that we later reviewed together. We could not record interviews because interviewees preferred to remain anonymous. ${ }^{3}$ 
We collected archival information to cross-check the interviews. We requested internal documents from the interviewees. We gathered information from the press, books, case studies, and analyst reports in both English and Korean. The archival information helped structure interview questions and to triangulate whether the comments were consistent with the documented information. As follows, we explain how we address specific empirical challenges.

Independence of uncertainty and controversy (potential multicollinearity)

The question arises of how often uncertainty and controversy arise independently of each other. We recognize that high uncertainty can be a source of controversy. In the BigMobile case \{high uncertainty, high controversy\}, the global financial crisis generated uncertainty and may be one reason why people had controversies about the timing of investment. In the SmallMedia case (also (high, high\}), concerns about cultural conflict were the source of controversy in the valuation process; the cultural concerns appear, in part, to reflect inexperience in the media sector, which was also the source of uncertainty. As we note above, though, we found multiple off-diagonal cases that we could use for the analysis (\{low, high\}: BigMedia, BigEnergy, Chip; (high, low\}: Apparel, SNS, Card).

Nonetheless, it is possible that such off-diagonal cases are outliers. Suppose the chaebol had engaged in 100 deals, and only six of them were \{high uncertainty, low controversy\} or \{low uncertainty, high controversy\}, our interpretations would still be accurate but would apply in relatively rare circumstances. Fortunately, although we could not determine precise distributions, the interviewees told us that there were a substantial number of cases with \{high, low and \{low, high\} uncertainty and conflict.

The frequency of off-diagonal cases arises for two reasons. First, the chaebol often seeks high uncertainty deals (due to the new opportunities that such deals provide), particularly deals where there is substantial agreement within the company about the value of pursuing the M\&A (i.e., low controversy). The following quotes reflect this point: "We know we need to undertake deals to find innovation opportunities [low controversy] although such deals are full of uncertainties [high uncertainty]." "Everyone agrees [low controversy] that we should do some moonshot projects [high uncertainty]." "We agree that we should find our next food [low controversy] in highly innovative deals [high uncertainty]." "We (the chaebol) recognize that we have grown [low controversy] by undertaking M\&A deals with extreme uncertainties in the history of Korean business [high uncertainty]."

Second, \{low, high\} low uncertainty and high controversy deals often reflect organizational issues within the chaebol, such as differences among managers in different business areas. Chaebols are highly diversified business groups in which managers are keen to protect themselves from others who might encroach on their business area. The following quotes illustrate this point: "We are not interested in many (financially) clear deals [low uncertainty] if the deals are not consistent with our goal [high controversy]." "Some [straightforward] deals [low uncertainty] can generate many debates if they are linked with organizational issues such as roles and responsibilities [high controversy]."

In sum, the variables may correlate, with uncertainty sometimes leading to controversy. Nonetheless, our data have three cases with each off-diagonal combination of uncertainty and controversy. Moreover, the interviews suggested that such cases are common.

\section{Other issues in data collection}

We recognize several other sources of potential biases that are common in qualitative research, including sample selection, non-random choice of interviewees, obtrusive 
observation, ex post rationalization and recall bias, complex causality, the possibility of confounding factors, and data censoring. Table 2 summarizes how we address these issues. In addition, Appendix 3 describes why uncertainty and controversy are unlikely to correlate with other factors that might drive M\&A evaluation methods, such as relatedness v. unrelatedness and cost v. revenue synergies; this means that our interpretations based on variation in uncertainty and controversy should have only limited bias arising from such omitted variables. No set of strategies can achieve complete confidence in any research-whether qualitative or quantitative-but we believe that these steps provide reasonable reliability in the results.

We sought to validate the concepts and implications with knowledgeable experts throughout the research activity and cross-checked information with archival records. We circulated our reports to the key interviewees (Laamanen and Wallin 2009) and then asked them for further opinions. These processes can lessen ex post rationalization bias and help triangulate our analysis. One of the authors has held an advisory relationship with the chaebol for several years. He meets top managers regularly and interacts with the corporate HR team. This relationship facilitated our data collection and triangulation process. We also discussed our concepts and initial interviews at a think tank meeting of the chaebol in 2011, with an audience of think tank researchers, executives, and external experts such as professors and consultants; their comments helped refine our interpretation.

We conducted interviews with an in-house expert, a former investment banker who has acted in many of the chaebol's M\&A deals since 2003. We asked him about our interpretations, comments from interviewees, and results. His feedback pointed us to additional interviews.

We assessed reliability in two ways. First, we presented our preliminary results at the corporate strategy and planning team (CSP) of the chaebol (May 2012). CSP team members and external experts with consulting relationships attended our presentation; the presentation and post-presentation interactions allowed internal and external experts to comment on whether our interpretations are correct. Second, as we noted above, we gathered archival information from media articles and internal records. These steps help ensure that the information we received is accurate and that our interpretations are reliable.

The cases include a mix of deals that reached completion (seven cases) and were not executed (three). In the three incomplete deals, we could observe the valuation methods used until the project was abandoned, but it is possible that the chaebol might have used additional methods if the acquisition had moved forward, which raises an issue of data censoring. Therefore, we ensured that each combination of uncertainty and controversy had at least one completed deal. On the other hand, it is desirable to consider both incomplete and executed deals, to ensure that there is no completion bias. All three incomplete cases involved high controversy; in itself, this is an intriguing pattern suggesting that controversy is particularly difficult to overcome, which provides an opportunity for future research.

\section{Stage 2: identifying M\&A evaluation methods (dependent variables)}

After selecting the ten cases, with their mixes of uncertainty and controversy, we continued with interviews in which we asked respondents to describe the methods that the chaebol had used to evaluate the deals. We asked our contacts among senior managers to introduce us to people with deep knowledge of the selected cases. Some of the top managers themselves agreed to become our interviewees; in other cases, they 
Table 2 Empirical issues in qualitative research and strategies to address

\begin{tabular}{|c|c|}
\hline Issues & Strategies \\
\hline Sample selection & $\begin{array}{l}\text { - Initial focus on identifying the contexts of potential acquisitions, } \\
\text { seeking to identify variation in uncertainty and controversy (the } \\
\text { independent variables), before turning to selecting cases and then } \\
\text { identifying valuation methods (the dependent variables). } \\
\text { - Extensive discussions with the chaebol of the relevance of the } \\
\text { ideas and implications. } \\
\text { o Discussions with the think tank at the chaebol of potentially } \\
\text { relevant contextual factors reinforced the importance of } \\
\text { uncertainty and controversy (the primary role of the think } \\
\text { tank is in-housing consulting, together with responsibilities } \\
\text { for macroeconomic forecasts, organizational culture, and } \\
\text { semi academic research). } \\
\text { o Follow-up interactions with former key interviewees. } \\
\text { o Circulation of our reports to the key interviewees and } \\
\text { other managers. } \\
\text { - Ex post presentation at the chaebol's corporate strategy and } \\
\text { planning team, as well as internal and external experts. }\end{array}$ \\
\hline $\begin{array}{l}\text { Non-random choice of interviewees, } \\
\text { obtrusive observation }\end{array}$ & $\begin{array}{l}\text { - Identified a wide range of knowledgeable executives based on } \\
\text { personal contracts, follow on suggestions from initial respondents, } \\
\text { suggestions from investor relations managers, and executives } \\
\text { identified in media articles. } \\
\text { - Discussions with external experts, including industry analysts and } \\
\text { academic scholars in Korea. } \\
\text { - Crosschecking of interviewees' comments with archival and } \\
\text { media information. }\end{array}$ \\
\hline Ex post rationalization and recall bias & $\begin{array}{l}\text { - Cross-checking through archival information and media articles; we } \\
\text { chose visible deals for which substantial information is available. } \\
\text { - Extensive discussions with the chaebol of the accuracy of the } \\
\text { information, plus discussions with the strategy and planning team, } \\
\text { an in-house M\&A expert, and external experts. }\end{array}$ \\
\hline Complex causality & $\begin{array}{l}\text { - Crosscheck our interpretation through discussions with executives } \\
\text { and analysts. } \\
\text { - Develop logical model of cognitive processes and integration with } \\
\text { the data. }\end{array}$ \\
\hline Confounding factors & $\begin{array}{l}\text { - Ex post interviews and presentation at the chaebol to identify } \\
\text { other factors that influence choice of valuation methods, either } \\
\text { directly or by shaping uncertainty and controversy. Deal size, } \\
\text { time limits, and habitual methods are possible factors. Size can } \\
\text { affect either controversy or uncertainty depending on cases. Time } \\
\text { limits are related with the perceived amount of uncertainty at the } \\
\text { moment of valuation, which is our focal analysis subject. Uncertainty } \\
\text { and controversy can explain the origin of valuation habits and routines. } \\
\text { - Although it is impossible to identify all confounding factors and to } \\
\text { analyze their influences in any study, this creates opportunities for } \\
\text { future research. }\end{array}$ \\
\hline Data censoring/internal validity issues & $\begin{array}{l}\text { - Most cases ( } 7 \text { of } 10) \text { were executed, including at least one case in } \\
\text { each combination of uncertainty and controversy. } \\
\text { - Balance of complete and incomplete deal to check whether results } \\
\text { remain robust. }\end{array}$ \\
\hline Affiliate-level effects & $\begin{array}{l}\text { - Interviewees are high-level executives, with careers in different } \\
\text { affiliates and divisions, who have a corporate-level perspective } \\
\text { on the deals. } \\
\text { - Affiliates coordinate with each other through formal and informal } \\
\text { networks (legally informal, although regarded as standard } \\
\text { [i.e., formal] in the firm). Every M\&A deal is reviewed by the } \\
\text { de facto headquarters ("central office") of the chaebol, which } \\
\text { reduces affiliate-level heterogeneity. } \\
\text { - Affiliates share similar document formats and approval processes, } \\
\text { producing (and reflecting) common organizational culture and } \\
\text { routines. }\end{array}$ \\
\hline $\begin{array}{l}\text { Non-independence of controversy } \\
\text { and uncertainty }\end{array}$ & - Discussed in the text, within "Empirical Issues in Stage 1" \\
\hline
\end{tabular}


contacted relevant managers and helped us to arrange interviews. Each interviewee also recommended other experts. In total, we spoke with 21 executives at this stage of the research, including 13 people who had not participated in Stage 1 of the research.

We also undertook 11 supplemental interviews: five with management consultants from three management consulting firms; three with the heads of the investment banking divisions of global banks that are leading M\&A book runners, underwriters, and advisors; two with senior executives from a law firm; and one with a local accounting firm that is actively involved in M\&A deals. The interviewees had M\&A experience with our subject chaebol as well as with many other deals. These discussions extended our understanding of different evaluation methods. The supplemental interviews and comments became part of our content if they included relevant information about our ten selected deals.

The categorization process for the M\&A evaluation methods proceeded as follows. Based on the information we gained from interviews and archival material, we sought to identify categories of M\&A evaluation methods as emergent concepts. The categorization procedure involved discussions among the authors, using our judgment about what characteristics were relevant to associate with each other. We also discussed the information from the interviews with knowledgeable industry analysts, to help refine our judgement. We found that it was possible to create four categories that clustered around common aspects within each category and substantial differences of characteristics across categories.

As we note in Table 3 and discuss below, we labeled the four cells as desktop valuation, capability design, issue lists, and storytelling methods. This labeling took place during Stage 2 of the research, when we investigated evaluation methods that the chaebol used for the cases. We settled on four categories of evaluations methods for two reasons. First, the data settled into the comparative categories, as we discuss below. Second, as in the choice for measuring uncertainty and controversy, additional variety in measuring evaluation methods would have required substantially more cases and interviews. Fortunately, the data provide meaningful implications with this measurement approach.

The next subsection describes the information that our interviewees provided for each of the ten deals and discusses the identification of the four evaluation methods. We group similar quotes of interviewees that reflect patterns within the cases. We reinforced the analysis with multiple interviews and archival documents.

\section{Desktop valuation}

Two cases illustrate valuation models similar to those that standard corporate finance textbooks recommend. For the Portal deal, the buyers sought to identify a range of target values and to construct sophisticated deal structures that met the interests of multiple parties involved in the deals. The evaluators used a discounted cash flow model, IRR, and simulation methods. The deal structure was complex because it involved three stakeholders. Nevertheless, given the amount of available information and consensus about the deal, interviewees noted that standard valuation models were appropriate and the models were sophisticated enough to cover complexities. The buyer hired an analyst from a credit rating agency to conduct the valuation, who told us that "While the deal structure was complicated, the valuation was straightforward." 
Table 3 M\&A evaluation with different combinations of uncertainty and controversy

\begin{tabular}{|c|c|c|}
\hline HIGH CONTROVERSY & $\begin{array}{l}\text { ISSUE LISTS } \\
\text { Cases: *BigMedia (BigEnergy, Chip) } \\
\text { - Example: unrelated diversification. } \\
\text { - High controversy: inconsistent with some } \\
\text { long-term views; many stakeholders. } \\
\text { - Low uncertainty: predictable customers; } \\
\text { well-known sector. } \\
\text { - Valuation focuses on finding the route to } \\
\text { minimum opposition/maximum consensus. } \\
\text { - The vision and long-term goals of a firm } \\
\text { are key terms and used frequently during } \\
\text { the valuation to convince and negotiate } \\
\text { with others. } \\
\text { - Valuation process includes identifying } \\
\text { possible sources of controversies } \\
\text { (issue lists) beforehand in order to develop } \\
\text { logic to overcome or adjust to the challenges. } \\
\text { - Financial valuations are used if they help } \\
\text { convince others. Financial valuation typically } \\
\text { is not useful for decision-making because } \\
\text { of never-ending debates on assumptions } \\
\text { but useful as a medium of communication } \\
\text { and a list of controversial issues. } \\
\text { - Lead by people with legal background. The } \\
\text { issue list method is also useful during due } \\
\text { diligence. Managers use this approach when } \\
\text { they need to compete about how to use } \\
\text { internal resources. }\end{array}$ & $\begin{array}{l}\text { STORYTELLING } \\
\text { Cases: *BigMobile (SmallMedia) } \\
\text { - Example: related diversification } \\
\text { into new geography. } \\
\text { - High controversy: competing } \\
\text { preferences and doubts about } \\
\text { whether to expand; limited } \\
\text { success in prior global expansions. } \\
\text { - High uncertainty: qualitative factors, } \\
\text { such as global risks and culture, } \\
\text { which are new for the buyers. } \\
\text { - Key activities during the valuation } \\
\text { process are designed to construct } \\
\text { stories. To be accepted, a story } \\
\text { should be stable during discussions, } \\
\text { simple, appealing to stakeholders, } \\
\text { and consistent with the buyer's } \\
\text { goals. The story should allow } \\
\text { maximum consensus with } \\
\text { informative decision-making. } \\
\text { - Strategy development precedes } \\
\text { financial analysis ("finance follows } \\
\text { strategy"). Valuation and strategy } \\
\text { development are inseparable. } \\
\text { Marketing, operation, and } \\
\text { turnaround strategies are more } \\
\text { important to evaluate the project } \\
\text { than financial valuation. } \\
\text { - Evaluation led by team of internal } \\
\text { staff, drawing on investment } \\
\text { bankers and lawyers to assist with } \\
\text { deal structuring and due diligence. } \\
\text { The higher the ranks of managers, } \\
\text { the more seriously the managers } \\
\text { take the storytelling methods } \\
\text { relative to alternatives. }\end{array}$ \\
\hline \multirow[t]{2}{*}{ LOW CONTROVERSY } & $\begin{array}{l}\text { DESKTOP VALUATION } \\
\text { Cases: *Portal (SmallEnergy) } \\
\text { - Example: acquisition of complementary } \\
\text { service. } \\
\text { - Low controversy: internal consensus } \\
\text { on the next steps to be taken and fit } \\
\text { with long-term plans. } \\
\text { - Low uncertainty: familiar business model } \\
\text { and stable technological trends. } \\
\text { - Financially oriented tools of standard } \\
\text { capital budgeting analysis: IRR, option } \\
\text { pricing, EBITDA multiples, sum of parts } \\
\text { analysis, adjusted present value (APV), } \\
\text { LBO analysis, and relative values. } \\
\text { - Structured process of merger valuation: } \\
\text { deal structuring, desktop valuation, } \\
\text { partnering analysis, due diligence, } \\
\text { negotiation, and updating valuation } \\
\text { iteratively. } \\
\text { - Evaluation led by investment bankers. }\end{array}$ & $\begin{array}{l}\text { CAPABILITY DESIGN } \\
\text { Cases: *SNS (Apparel, Card) } \\
\text { - Example: new business model } \\
\text { with potential complement to } \\
\text { existing business. } \\
\text { - Low controversy: urgency to do } \\
\text { a new project, consistent with } \\
\text { the will of top management. } \\
\text { - High uncertainty: unclear business } \\
\text { model and market. } \\
\text { - Little initial financial analysis. } \\
\text { Instead, valuation constructs } \\
\text { decision-making process to } \\
\text { achieve maximum information/ } \\
\text { minimum ignorance. } \\
\text { - Financial analysis is used to } \\
\text { develop plausible plans, not } \\
\text { to assess investments; substantial } \\
\text { burden to rationalize the uncertainties } \\
\text { to bear at each contingency. Target } \\
\text { value determines whether and which } \\
\text { uncertainties to accept. } \\
\text { - Evaluation led by management } \\
\text { consultants. }\end{array}$ \\
\hline & LOW UNCERTAINTY & HIGH UNCERTAINTY \\
\hline
\end{tabular}

The table provides examples of the four categories of evaluation

*The cases the table focuses on (cases in parentheses are other representative deals)

The buyer estimated revenue in two steps. First, it estimated the change in page views and log-in users after the merger. The buyer had a large number of log-in users but had a weak search engine. Portal had a small number of log-in users but owned a 
strong search engine. The complementarities allowed estimating the change of page views and log-in users from the sum of the views and users of the two services. Second, the buyer computed advertising and other revenue per user in a similar fashion.

Portal: "One of our team members is from a credit rating firm. He computed the target's value using five different quantitative techniques. As a result, we can obtain the range of target values upon which we set initial bidding price and upper limit."

For SmallEnergy, the buyers sought to identify the direct financial impact of the deal, as well as to consider the benefits of blocking a foreign competitor from using the target to enter the buyer's home market. The buyer evaluated the deal as if the target was one of its divisions and plants. Considering the size of the buyer, the target had a moderate size, similar to the size of projects that the buyer had conducted many times in order to extend or alter existing activities. The buyer applied standard valuation models, using performance indices and tools such as earnings before interest, taxes, depreciation, and amortization (EBITDA) multiples, comparables, and standard discounted cash flow.

SmallEnergy: "The deal is not small, but so simple that we did not even hire investment bankers or consultants." "We used multiple valuation methods. EBITDA multiples tended to produce the most reliable valuation." "If the target becomes unprofitable, we can simply disassemble plants and build apartments on the site instead. That pays back our investment." "We do not prefer discounted cash flow (DCF) models because they assume too much, but DCF is a convenient initial tool that helps us consider many variables. Our favorite for final decisions is EBITDA multiples."

The investment bankers we interviewed used what they referred to as "desktop valuation" at the initial stage of deals with low uncertainty and low controversy. Desktop valuation employs ranges of standard techniques such as net present value (NPV), internal rate of return (IRR), valuation multiples, leveraged buy-out (LBO) valuation, and relative values. Thus, desktop valuation applies the most standard valuation models and derives ranges of valuation that become useful during the bargaining process.

Investment bankers: "We first determine exit value using trading multiples in IPO markets, for example. Then, we determine leverage. Finally, we set target IRR. Valuation leads to solutions for leverage conditional on the exit value, leverage, and target IRR jointly." "This booklet is one of our manuals to do valuation in standard situations. We have well defined methodologies and processes for valuation." "We often use the methods that previous deals have used."

In sum, in these cases, the buyer emphasized conventional financial methods of M\&A valuation, such as net present value, comparables, IRR, payback period, LBO valuation, and EBITDA multiples. We use the term desktop valuation to refer to these methods, based on a term common among investment bankers. Appendix 4 summarizes discussions about desktop valuation tools mentioned in the interviews.

\section{Capability design}

For three cases, valuation reflected a set of approaches that we refer to as the "capability design" method. Capability design means using the M\&A evaluation process to decide what capabilities the firm needs in order to achieve its long-term goals and how the potential target might help the buyer create those capabilities. Standard financial models 
may be used in such cases but as supplements to capability design, rather than as the primary drivers of valuation.

In the Apparel deal, the buyer used the evaluation to help advance its plan of becoming a global player in the fashion industry. The buyer conducted valuation analyses to discover ramifications of acquiring design capabilities for its value chain. It applied scenario planning instead of standard financial valuation approaches in order to develop plans and strategies about how to use the acquired design capabilities. The plans and strategies suggested how much the buyer could afford to pay for the target.

Financial analyses assisted with scenario planning. For instance, the buyer used financial analysis in order to set goals and develop performance indexes and compensation systems for creative talent, as opposed to using the analysis to discover the target's value. One interviewee stated, "Valuation was also for creating a vision and building capabilities consistent with that vision, not for estimating the target's value from the analysis about [exogenously] predetermined cash flows." Another argued that financial valuation was "harmful because it could reduce the buyer's strategic flexibility and limit the full use of our resources." Clearly, time limits can force managers to decide without quantitative information, which can increase uncertainty.

Apparel: "We assessed what the implications to the entire value chain would be if we had acquired the fashion firm with design capabilities. We developed possible scenarios of synergies in our value chain. We conducted rough financial valuation because it helped us to understand scenarios." "The core of valuation was to develop the measurement and compensation system for creative talents, which would be used after integration." "Our valuation for the target was the sum of real estate value, enhanced bargaining power, the opportunity cost of building the target's business, and new business potential. Measuring the opportunity cost required evaluating and enhancing our capabilities about couture design at the same time. Increasing the value of the new business potential essentially became our goal and vision. Thus, valuation was not about estimating future cash flows. It was more about visioning and capability building about our growth." "Speed was important to make the deal successful ... we could not wait completing comprehensive financial analysis." "Financial valuation may be insufficient or reduce our strategic flexibility. Textbook methods can be destructive in this deal."

The Card deal also demonstrates capability design approach. The buyer used the evaluation to identify opportunities to gain synergies with its existing wireless business. The buyer first investigated what resources and capabilities (the buyer called them "R\&C") they needed in the era of technological and market convergence. Next, they examined how much it would cost to acquire the resources and capabilities. If the cost was within the budget predetermined at the last period, the buyer would consider investing; otherwise, the buyer would wait. The buyer used such valuation processes to formulate investment targets, determine required resources, and settle on potential investment. This approach is similar to an exploration tool (March, 1991), while strikingly different from the use of standard financial models to evaluate investment opportunities with given cash flows and size. Instead, the valuation process formulates cash flow and investment size conditional on the buyer's goals.

Card: "We had difficulty in evaluating financial firms because of the financial crisis. However, we acquired the target because it had been our goal for a long time, and the 
crisis lowered the offer price of the target to meet our budget. ... We needed the target's resources and capabilities. We had asked how much we had to pay to obtain the resources and capabilities. Once the offer price became affordable, we purchased the target." "As far as we could develop vision and strategic plans, we would buy the target. Its valuation numbers and uncertainties are less relevant." "Uncertainties over financial crisis made quantitative analysis less useful. Formulating plausible strategies and capabilities became more important in valuation."

Similarly, the SNS deal did not depend on standard valuation models. The buyer used the evaluation to help assess strategic opportunities in an evolving industry. In doing so, it created and assessed scenarios in which Target value $=$ Constant $\times$ (\# of customers $)^{2}$; the constant was based on qualitative assessments of the opportunity, using several scenarios about the parameter. Moreover, instead of beginning with quantitative financial analysis, the buyer concentrated on understanding what the target's business model was, how to create synergy, and what business model to design for the combined firm. Then, the buyer formulated plausible strategies about how to use the target's unfamiliar business model, which in turn determines valuation.

Based on the plausible strategies, the buyer decided how much to invest and what resources to commit and developed a roadmap and role of the target within the buyer's long-term goals. These decisions became part of the basis of deal value, although the buyer acquired the target even before it completed the analysis and then spent several years finalizing the strategies. Hence, rather than fully financially evaluating or even understanding the target, the buyer studied what factors it could leverage in the target and surrounding dynamics of the Internet business.

SNS: "The more detailed or rigorous our valuation model becomes, the less useful to develop plausible and flexible strategies. Developing detailed and rigorous strategy should be first. They determine the goal and projections about cash flows and risks" "Although no one can understand the target's business model [one of the first social network services in the world], we just felt there was something. Then, our valuation meant how to understand the service, how to integrate the service to our portal, and how to generate cash from the service. We use valuation tools in order to study the buyer. We set our bidding price based on the study." "We analyze uncertainty qualitatively using the variations of strategies, scenarios, and management consulting frameworks." "The deal was a good opportunity to study Internet businesses, which was in fact one of the goals on the deal." "We valued the experience of conducting this kind of deals. This will enhance our capabilities to acquire larger players in future."

\section{Issue lists}

In three cases, evaluation converged to conflict-equilibrating approaches (Nelson and Winter 1982) such as forming coalitions, building consensus, bargaining, aligning incentives, and balancing conflicts of interest. Standard financial valuation methods do not suit this purpose because subgroups may not reach agreement on issues concerning models, assumptions, data, estimation methods, and interpretation and, instead, use financial models to generate valuation numbers that suit their aims. Our M\&A cases reveal evaluation processes that focus on resolving lists of issues that are generating controversy among stakeholders. We call this practice of M\&A evaluation the 
"issue list" method, where the label arises from a buyer who developed lists in order to identify challenges that might arise in a deal.

A key purpose of the issue list method is to create a common goal about a deal. This point illustrates the idea that the value of some deals is socially constructed and endogenously formed, rather than existing as a pre-existing number that will be discovered via financial tools. Quantitative evaluation is useful as supporting analysis for the issue list approach as far as financial valuation helps validate stakeholders' perceived value, vision, and strategy for a deal. If analyses conflict with the goals, then managers tend to update the quantitative models until they generate "intuitive and legitimate" numbers.

BigMedia illustrates how a deal's value can be socially constructed via interactions between a powerful manager's preferences and less powerful managers' incentives. Those involved in the deal used quantitative models for the deal but used the results to reinforce political and organizational interactions rather than to provide objective facts. Different people in the case used similar quantitative models to come up with vastly different numbers, depending on their starting point assumptions and goals. The interviewees commonly believed that "it was a waste of time to argue with algorithms and assumptions in a financial model"; as one interviewee put it, "professionals rarely do such a thing; only amateurs do so." Another interviewee told us that "the mind of those who control the target matters most, and this control right cannot be objectively valued given the preferences, contexts, and goals of stakeholders." In practice, the value of the deal was set and finalized only after powerful managers on both sides of deal met. As one person put it, "We formulated the deal value over drinks."

BigMedia: "Valuation was a consensus building process." "The will of the owner matters. The goal of this complex process of valuation is about how to convince the owner and to make the deal legitimate." "The tastes of stakeholders are important. For example, buyers often argue that valuation does not matter much because we want to keep the target forever. That is why expectations of management is important in any merger deal. They often call the buyer's taste a long-term goal, vision, the will of the owner, face saving, and pride. Who convinces the owner and how to convince the owner ultimately matter most in valuation. Hard numbers are not always a good way of convincing people." "Who controls the buyer can determine valuation. For instance, some stakeholders do not mind overpaying for the target because they feel uncomfortable if the stock price becomes too high. Imagine that if you want to transfer your control rights of the buyer to your children. A high stock price would increase taxes and reduce capital gain opportunities of your kids." "To some owners, their firm is like their children. How do you think you can do valuation for your children in order to sell them to others?" "We generated a list of what stakeholders wanted or worried about in order to address them and execute the deal." "We formed a syndication to buy the target. But all our partners have different interests and preferences over the deal structure. We do valuation in order to balance the interests of our partners and derive equilibrium in the deal." "Domestic deals tend to be 'size plays' [Korean firms may buy Korean firms in order to increase size-unrelated diversification is common]. Cross-border deals tend to be 'pure plays' [Korean firms may buy foreign firms to create synergies-related diversification is common]." "People might have an opinion about what a fair price of the target is. But they argued with each other for their own manipulated numbers. Negotiation between top 
managers eventually determined the value." "Tens of million dollars changed in valuation while top managers drank sake together. It means (financial) valuation can become insignificant in some cases." "In order to reduce the opposition from existing teams, we needed to construct the deal's positive spillover to their capabilities."

BigEnergy vividly shows how deal value can emerge through intensive discussion and interactions involving opposing coalitions. There were two opposing coalitions within the buyer, both with very strong opinions and confidence in their points of view. The coalitions engaged in bargaining and negotiation to support or block the deal.

One coalition read the mind of the powerful CEO and proposed a deal in line with the leader's preference. This coalition included executives who had investment banking and deal experiences, together with an M\&A boutique whose owner was a friend of the CEO. The coalition's strategy was to stress the vision and big picture of the desired business portfolio. "They designed quantitative models and business plans that reinforced their picture and their preferred potential of the proposed deal."

The other coalition was less powerful. The group included junior executives and operations experts, who would be responsible for post-merger integration. The junior coalition was cautious about expressing their views because they knew what the CEO wanted and did not want the leader to have a negative impression of them. Therefore, they built a coalition with outside stakeholders and implicitly expressed their opinions through the external actors. They stressed "how bondholders and shareholders would react to the deal", supporting their argument by submitting a stakeholder opinion. They hired outside experts to investigate failures in similar cases of competitors and foreign firms, intentionally creating a sample selection bias. "Focusing on implementation challenges and external validation of their views, the junior coalition sought to convince the CEO and key personnel that the deal was not viable at that moment and that the company should instead rethink it in the future." The deal was eventually discarded.

BigEnergy: "Both the opponents and supporters of the deal used similar valuation methods, but with vastly different results." "M\&A boutiques and some top executives read the preference of CEO toward energy businesses in North America. They came up with a seemingly attractive target." "The CEO told me to review the deal from the positive and constructive perspectives." "I had to rely on the view of external stakeholders and find alliance to convince the mainstream view. We were not capable of telling our opinions explicitly to the CEO." "One side argued that the deal was in line with our long-term vision of being a global player. We proposed that the deal was against our objectives and organization culture given its balance sheet impact." "Since powerful managers supported the deal, I could not visibly oppose the deal. I questioned item-byitem the details in the deal instead of opposing the big picture." "Both sides found success and failure cases to support their arguments." "It was hard to convince others with facts. People always had different interpretations. Vision was a very strong tool to make a project look attractive." "The deal showed how vision and people's preference determined valuation numbers, not the other way. People did not like a deal because a deal had positive NPV; rather people made NPV positive if they liked a deal." "I cited the behaviors and situations of our competitors to convince opposing parties."

Chip shows that valuation involves a process of integrating and balancing different views. Two perspectives bound the range of premium (acquisition price-current stock 
price). If the premium was very low, some people would suspect that the government was giving the chaebol preferential treatment. By contrast, internal objections would strengthen if the premium was too high, even if top managers tended to support the deal. To gain broad support, therefore, valuations needed to generate results within the bounds of the two perspectives.

In parallel, the valuation model needed to consider two competing views about the deal. One view argued that the deal was primarily to generate positive spillovers to other subsidiaries in the chaebol. For example, the target had recovered from near bankruptcy and became a major global player even without apparent resources such as financial and technological capabilities. "Transplanting the latent success factors of the target can make the member firms of the chaebol more competitive in the global market. The chaebol has been a domestic player. Being a global player has been a supreme vision of the chaebol. The target will give much needed global capabilities to the chaebol." The other view argues, "The deal is the source of new growth." The chaebol had made large M\&A deals every 20 years through which it has owned leading energy and telecommunication companies in Korea. "Acquiring the chip should be regarded as the third wave to the chaebol." Such controversies produced a series of sub issues that became the subject of more controversies.

In the face of the controversies, valuation models and results depended on which view the acquirer adopted. Eventually, top managers regarded the deal as the third wave to the chaebol. Valuation models were designed to reflect the dominant view.

Nevertheless, the valuation also needed to consider less dominant logics such as synergies and how to model enhanced capabilities in global markets. There were also subgroups that opposed the deal, who brought Excel files filled with negative NPVs and small IRRs. Such views were rejected, but their legacy remained and was incorporated in the master excel file. Hence, valuation was a process of balancing and integrating opposing views.

Chip: "Valuation is important for analyzing the different opinions of managers. Managers opposed to the deal brought very negative valuation results. Those for the deal generated highly positive valuation numbers. We need to create one file that balances the models from managers with different opinions." "We had experience in highly controversial deals such as acquiring a media firm. I am not saying financial valuation is unimportant in controversial deals. In that case, valuation (especially discounted cash flow method) is useful to discuss the issues in target firms, to communicate goals, and to simulate diverse opinions. It gives us consensus... It is great to have a valuation file that summarizes issues and their solutions." "Some people emphasize synergy with the target. If we adopted the view, the process of post-merger integration would be different. Yet, we incorporate their views in the valuation model. This increased the premium and decreased internal oppositions." "We have to convince creditors and government officials that our proposed price was neither too low nor too high." "We did the deal for the sake of the Korean economy. We were patriotic. This was an important issue and significant part of valuation." "We did not explicitly model the capabilities of the target. The target had succeeded in the global market even without financial and technological capabilities. Some people brought valuation frameworks that explicitly evaluate the capabilities. I thought such capabilities surely were valuable, but should not be incorporated in the financial valuation. We just regarded them as additional and un-modeled value of the deal." "Quantitative valuation model tends to evolve with the emergence of issues." 


\section{Storytelling}

In two cases, evaluation became similar to the socio-political capital budgeting approach that Bower (1970) described, again significantly deviating from standard financial approaches. The socio-political approaches in the two relevant cases were hybrids of the capability design and issue list methods. In doing so, the decision-makers sought to tell plausible stories that would satisfy multiple coalitions. We call this practice the "storytelling" method.

The storytelling evaluation pattern is similar to Bower's (1970) organizational processes but with differences. Bower's model describes a process in which business-level managers initiate investment requests, middle-level managers integrate the behaviors at the corporate and business levels, and corporate management designs the structural context (rules of the game) to guide projects in a strategic direction. In our cases, by contrast, low-level managers did not propose the deals, nor did they explicitly intervene in the decision-making process about such deals. Instead, they tended to support more senior managers in collecting data and providing logic to support their boss's opinion and help implement deals. In our cases, initiation, integration, and structural context emerged at the top manager level.

BigMobile illustrates the storytelling approach. The buyer first outlined possible outcomes of the deal and then conducted financial evaluations that helped build consensus around the implications of the deal. The interviewees said, "No one believed the specific numbers that the quantitative tools generated in this context. However, that practice facilitated investigation and discussion. The primary purpose of the models was not to evaluate the investment opportunity but, instead, to reinforce satisfying and plausible stories about the deal." The quantitative models became more sophisticated than necessary, even esoteric, "in order to demonstrate that the analysts were working hard - and to make critiques harder." The interviewees reported similar practices for operating plans, in which "financial models got complicated in order to use them for implementation plans and schedules."

This case thus illustrates the point that the evaluation process can help stakeholders construct and tell stories in support of their goals. Subgroups with the strongest combinations of concrete and intuitive stories tend to win the debate about the deal. The interviewees suggested that storytelling about the merger deal should be intuitive and powerful. Indeed, "relying on complicated financial models can damage stories, inviting endless debates about assumptions and making it difficult to relate meaningful arguments to senior managers." The interviews also suggested that integration and operation strategies were important parts of this storytelling process. Those strategies helped reduce concerns about uncertainty, allay doubts about the buyer's capabilities, please related teams, and explain the deal to managers who would be responsible for the implementation process later on. The interviewees also noted that benchmarking analysis documenting similar cases would help convince others.

BigMobile: "Those with convincing stories won the debate over the deal. Valuation was a way of telling the stories." "The urgency of the deal influenced valuation-it was different from real options. In real options, an option is exercised when its exercise value is greater than continuation value. In our case, timing and situation determined how to decide the value of the target. Timing is the function of the owner's will, internal pressure for performance, new visions, etc." "Describing similar cases (benchmarking) was more impactful than valuation. The purpose of valuation was to learn and replicate the intuition from benchmarking analysis." "The board of directors 
in the target opposed the deal strongly." "Since several top managers wanted large scale foreign investment, we needed to be very careful at expressing our opinion."

The evaluation process for SmallMedia was similar to BigMobile. The buyer regarded financial valuation as a framework that helped people tell convincing and plausible stories rather than assess the deal; quite simply, the results of financial valuation were less important than the process of financial valuation. The buyer found, "The key factors were qualitative elements such as human capital, culture, and entertainment content." SmallMedia interviewees even regarded the debate about numbers as "amateurish," viewing the financial valuation as "not serious." Instead, important factors to determine whether the story about the deal was compelling included a concise summary of the deal, detailed operational plans, the relationship to the buyer's existing vision, and descriptions of next steps. Such storytelling "focuses on the potential of the deal, which became the basis of the offer price."

SmallMedia: "We of course discussed valuation numbers, but knew they were not a decisive factor to determine investment. The buyers, the target, and other people could always come up with the numbers from their predetermined view. Everyone could offer plausible stories about uncertainty, but those with the negotiation and implementation experience in similar deals offered the most plausible stories." "We were too professional to argue over the valuation techniques." "Stories that outlined the potential of the deal significantly saved our time and effort, the most valuable resources. They also allow us to focus on the big picture." "In determining the value of the target, we investigated which stories and scenarios had been the best. During valuation, we often developed the story together." "Financial valuation was nothing but a framework-only one of many frameworks we employed. The argument for the deal needed to be simple and straightforward." "When people had little knowledge and different opinions about deals, no one would believe valuation number. People instead relied on strategies and intuitive explanations." "Instead of detailed financial valuation, we spent more time discussing detailed implementation plan after the deal." "Financial valuation had been less important in the entertainment sector. The insight to evaluate human mind and culture was more important. Operations strategy also was important."

Christensen et al. (2011) emphasize the importance of operational plans during deal evaluation, based on the point that firms make frequent mistakes in evaluating the challenge of integrating a target. The logic underlying our argument differs from theirs because we posit two underlying socio-political factors, uncertainty and controversy, that shape how firms include implementation plans as part of deal evaluation. We regard Christensen et al.'s (2011) methods about evaluating business model-reinventing deals as a combination of issue list and capability design methods but with less focus on socio-political factors.

In sum, these cases are hybrids of issue list and capability design methods. The evaluation processes focused on constructing intuitive, powerful stories that sought to balance the interests of key stakeholders. Financial evaluation in this context is useful as a framework for information processing and communication but is less important as a formula for generating numbers upon which to determine investment.

\section{Stage 3: how does evaluation vary with uncertainty and controversy? (matching dependent and independent variables)}

As we identified the four categories of valuation methods in the previous section, we found that they aligned quite closely with the four states of high-low uncertainty and 
controversy (Table 3). The remainder of this section describes the evaluation method and its match with a combination of uncertainty and controversy, interprets the reasons for the match, and assesses the relationship to prior literature.

\section{Desktop valuation methods: low uncertainty and low controversy}

The two cases in which both uncertainty and controversy were low aligned with desktop valuation methods. Desktop valuation includes techniques such as discounted cash flow and its variations-including NPV, IRR, option pricing, EBITDA multiples, sum of parts analysis, adjusted present value, LBO analysis, and relative values. Interviewees said, "People use these financial formulae in order to derive a range of target values. The range allows buyers to set an upper limit of M\&A valuation, which becomes important during bargaining with sellers to ensure that we do not over-pay." Well-defined routines help implement the formulae. Several interviewees noted industry variations in the desktop valuation methods, "Telecommunications and service industries tend to prefer multiples (e.g., economic value and/or EBITDA), while the financial sector prefers discounted cash flow." "Such traditional methods do not rule out qualitative assessments, but most commonly as a follow on to the financial analysis as part of the process of selling a deal to multiple stakeholders." We also found that the choice of method has implications for who leads the assessments, "People with investment banking experience are good at and tend to take charge of desktop valuation."

This match of desktop valuation with low uncertainty-low controversy reflects a clear explanation that arose in the interviews. The respondents noted, "The more accurately people could compute the underlying value of a deal and the greater the agreement about underlying assumptions, the more feasible a valuation method becomes." This pattern aligns closely with basic financial economic models of M\&A evaluation (e.g., Brealey et al. 2005; Ross et al. 2009).

\section{Capability design methods: high uncertainty and low controversy}

We found that capability design methods arose with the three cases with high uncertainty and low controversy. These tools typically involved making assumptions about what hypothetical opportunity a deal offers in developing capabilities at the acquirer in constructing the supporting logic for deals. Interviewees illustrated capability design methods as forms of scenario analysis and goal-setting techniques in framing and investigating the assumptions.

Cases with high uncertainty encompass substantial equivocality about the nature of a deal. Capability design during the M\&A evaluation process helps managers decide "what capabilities we will need in order to achieve our goals and how the target helps us create those capabilities." Enhancing firms' capabilities is an important goal of many M\&A, often cases with large acquisition premiums (Laamanen 2007; Uhlenbruck et al. 2006; Berry 2006; Hasan et al. 2011).

Financial valuation models are less likely in such cases because evaluators struggle to identify reliable parameters in the face of high uncertainty. Instead, "buyers focus on identifying the causes of uncertainty, assessing the extent to which uncertainties affect deal performance, and determining strategies to address uncertainties." After such 
qualitative assessments, firms then commonly derived a value of the merger deal (i.e., the offer price) that would be consistent with bearing the uncertainties.

Capability design cases had implications for how the firms used financial models and for the personnel who lead the evaluation. Financial models were often used in such cases but as supplements rather than as primary drivers of deal valuation. The lead personnel for capability design cases included in-house and outside consulting teams, often consisting of people with MBA education and/or consulting experience. Moreover, even when investment bankers undertook due diligence of capability design projects, "we often hire strategy consultants to analyze the implications of the uncertainty and help modify the analysis", i.e., complementing desktop valuation to reflect the concerns that arose during discussions about uncertainty "if desktop valuation is possible."

One can view the capability design methods as attempts to avoid uncertainty (Cyert and March 1963). The methods help achieve maximum knowledge (minimum ignorance) in decision-making under high uncertainty. In parallel, the approach implements the minimax principle, in which agents seek to bound uncertainty by minimizing maximum possible losses while seeking to gain large profits (Epstein 2001).

In our cases, capability design appeared in two principal forms, scenario planning and goal setting, although a few interviewees also mentioned enterprise risk management. Minimax implementation in this context follows from identifying scenarios that assess information about markets, trends, and capabilities of involved parties. Our case studies show that the valuation process aims to identify worst- and best-case scenarios, while "we prepare for various scenarios by designing contingency plans, options, and contractual terms such as indemnity clauses and escrow accounts." The best-case scenarios provide targets to aim for, while the worst-case scenarios help even risk-neutral firms avoid negative extremes, either by avoiding or redesigning deals; interviewees said, "We design deals to avoid the negative scenarios."

Scenario planning helps clarify which elements of uncertainty a buyer can influence and what strategies help address the uncertainty. Scenario planning also assesses "how much value a target needs to create in order to make it worthwhile to take on the uncertainty." In essence, evaluation aims to "maximize controllability and growth options by choosing or constructing desired projects." In this way, even risk-neutral firms seek to avoid the extremes of uncertainty (Boudreaux and Holcombe 1989; Gilboa and Schmeidler 1989).

Goal setting, the second tool, also is an important instrument in capability design methods. Rather than estimating valuation parameters, interviewees set goals for critical variables and develop implementation plans to achieve these goals. Hence, "we do the evaluation in order to create opportunities as well as estimate value of a given opportunity."

An interviewee described goals as roadmaps, "The amount invested is the amount required to follow the roadmap." In essence, goal-setting activities seek to adapt to uncertain environments by organizing a firm's routines to deal with the uncertainties. For example, "attaining the desired value of a deal is a goal; post-merger integration strategy is an example of an implementation plan to accomplish the target value of the deal; next we use financial models to compute deal value." We can interpret such comment of interviewees as backward induction.

As part of scenario planning and goal setting, "Valuation is an important framework to acquire information under uncertainty and to strengthen our core capabilities using the deal. We use benchmarking with comparable cases to develop strategies. This helps address uncertainty and facilitates decision making." "Gathering information about new 
industries, culture, human resources, business practices, and different markets can help design implementation plans during post-merger integration as well as identify further expansion opportunities."

This finding is consistent with ideas concerning organizational learning (e.g., Levitt and March 1988). Muehlfeld et al. (2012) suggest that learning from experience shapes the likelihood of completing uncertain deals. M\&A processes are complicated and filled with uncertainties. In such contexts, prior experience can enhance capabilities of future expansion opportunities (Shane 2000).

This process again speaks to the endogeneity of deal value. The M\&A evaluation activities of scenario planning and goal setting suggest that a buyer in a context of substantial uncertainty does not simply uncover some pre-determined underlying value of a deal but instead works in uncertain environments to conceptualize values, plausible strategies, and plans. That is, evaluation in the presence of uncertainty is as much or more about creating a viable project than about assessing the underlying value of a project.

Importantly, capability design requires low controversy. When faced with high controversy, the capability-design approach is likely to fail, owing to goal conflict. Goal setting tends to require common goals. Similarly, scenario planning will struggle under high controversy because sub coalitions will disagree about possible scenarios and their relative weights.

\section{Issue list methods: low uncertainty and high controversy}

The three cases with low uncertainty and high controversy used issue list methods. These involved a set of tools that clustered around techniques for resolving controversial issues. These tools commonly involved creating coalitions and negotiating issues. The negotiations commonly involved an iterative sequence of discussion and deal changes, frequently involving substantial refinement of the nature of the potential deal as discussions within the acquiring firm proceeded. With this set of techniques, the firm commonly used financial analysis as a second step "to help support the deal preferences" that emerged from the discussions.

When controversy is high, "the attractiveness of a deal depends on how well the structure of a deal addresses items" in the issue lists. In these cases, evaluation became an exercise in reducing and/or compartmentalizing controversy that threatened the deals; indeed, the deals in our sample that were least likely to reach completion had substantial controversy. The deals often were modified during the evaluation in order to maximize the number of satisfied items in an issue list; hence, the issue lists influenced the nature of the deals. The discussion here draws both on the cases and from the supplemental interviews with investment bankers, lawyers, and consultants about their experience with similar deals.

Issue list approaches have three properties: identifying goals, building consensus, and dealing with long-term strategic interests. First, the value of a project tends to emerge from beliefs in a social context rather than from exogenous sources of objective reality. In such cases, "we need to identify potentially competing goals and explain past practices, provide benchmarking cases, and/or stress norms of lessening differences of opinion" between stakeholders such as opposing managers. Then, a firm assesses whether an M\&A deal "corresponds to the strategic direction and other norms of important stakeholders" (i.e., constructs issue lists) in order to determine whether a deal is feasible and "to attempt to build consensus around the value of the deal" or "maximize support and minimize opposition." 
The more successful a deal is in addressing goals and the greater the validation from stakeholders that the deal is consistent with their goals, the more attractive the deal becomes. The greater the controversy about a deal, the more salient such relationships become.

Second, the approaches seek to "draw stakeholders into supporting proposed deals and cooperating during the integration process. Such support is important in executing and implementing a deal." "If powerful subgroups do not agree on the viability of an implementation plan, a deal will need to be reconsidered regardless of its estimated financials." Similarly, a firm constructs deals not only to maximize benefits but also to "balance the interests of stakeholders." Thus, instead of applying standard valuation formulae, a firm will attempt to "redesign deals to be consistent with stakeholders' agendas" (e.g., reflecting an issue list). "The more successful a deal is in drawing positive attention from stakeholders, the more attractive the deal becomes"; this becomes increasingly important as the diversity of opinions among stakeholders increases.

Third, issue lists approaches are "important in applying long-term strategic implications." Controversies about strategic goals can occur in many patterns. Owners often favor deals that would enlarge their empire, while minor shareholders are often more conservative; "managers in charge of growth strategies often are keen to find deals, while managers responsible for current customer relationships often object."

During follow up of the research, we observed a Korean firm set up an M\&A execution team dedicated to identifying and executing deals; the team consisted of former accountants, lawyers, and investment bankers with M\&A experience. Despite its aggressive mandate, the team was cautious and focused on risk management because failures would damage the members' careers; their caution generated conflict with strategists who sought growth. The issue list method can help balance interests and alleviate stakeholders' concerns in such cases. "The more a deal equilibrates the interests of stakeholders, the more attractive the deal will be."

We found that issue list evaluations were often led by lawyers or executives with legal backgrounds. M\&A law firms commonly keep manuals similar to issue lists, which aid lawyers in checking the sources of controversies and legal issues that may arise during the M\&A agreement process. Our interviewees suggested that M\&A lawyers had skills relevant for evaluating controversies. As in the capability design approach, "investment bankers often helped modify valuations to incorporate discussions" about controversy.

The notion of issue lists in cases of high controversy aligns with research in organizational legitimacy (e.g., Sanders and Boivie 2004; Higgins and Gulati 2006). Approaches under this combination seek to establish a consensus or dominant coalition around a vision and long-term strategies in order to legitimize a deal, emphasizing the role of coalition-building in determining social and economic behaviors (Giddens 1979, 1984; Weick 1979). If a deal lacks legitimacy, the deal as well as the firm pursuing the deal will lose value (Cohen and Dean 2005). In addition, legitimacy is important to access resource and to obtain the capital for deals (Zimmerman and Zeitz 2002). Legitimacy can come from the perceived relationship of a deal with long-term strategies, vision, and experiences. Indeed, integrating a firm with such a perceived relationship tends to enhance pre-acquisition valuation and acquirer performance (Laamanen and Keil 2008). In addition, prior resource allocation and communication influence post-acquisition coordination outcomes. Subgroups approach problems with diverse experience, cognitive processes, goals, values, and concerns. This leads to controversies (Agarwal et al. 2012). This 
logic suggests that M\&A evaluation often is not merely a financial reckoning but also inherently a social calculation and process.

In parallel, the pattern of generating issue lists to facilitate negotiation among coalitions aligns with Wood and McKinley's (2010: 73) argument that the level of consensus among knowledgeable peers determines whether an entrepreneurial opportunity is objectified or abandoned. Objectified opportunities become enacted "through entrainment of stakeholders into a consensus to support the opportunity." Social ties and reputation are important factors in the entrainment process. Christensen et al. (2011) emphasize that stakeholder expectations shape which targets a firm selects and how much disruption the firm is willing to incur in its M\&A strategies. This argument corresponds to our finding that the issue list method to building consensus determines the perceived value of a merger deal. Overall, the patterns highlight the importance of social relationships, including social ties, status, reputation, and norms that reinforce private preferences in M\&A deals.

\section{Storytelling methods: high uncertainty and high controversy}

The two cases when both uncertainty and controversy were high emphasized storytelling methods. This set of tools commonly involved developing extensive logics for why or why not the deal made sense, based on the perspective of the actor who was developing the argument. The storytelling term arose in several interviews (some interviewees also used the term "investment thesis" for this context).

When both uncertainty and controversy are high, firms may hire consultants, investment bankers, lawyers, and accountants to provide advisory services and due diligence. In storytelling, such experts offer diverse perspectives on an M\&A deal. The multiple insights help firms carry out capability design and issue list activities. For instance, project teams need to show that "they have checked issues that have generated controversy about a deal" (issue list method). In parallel, "through consulting activities, project teams often make efforts to produce capabilities and knowledge that will help avoid or address uncertainties about a deal" (capability design method). Ultimately, executives who report to senior managers integrate information to construct a coherent story about the deal. Using the diverse information, "top managers discuss whether a deal demonstrates convincing and plausible stories about opportunities for the buyer's future."

Sanders and Boivie (2004) suggest that such socio-economic sorting is important for valuation under high uncertainty and conflicts of interest. Putting the implications of the capability design and issue list activities together is inherently a socio-political process. One can view the storytelling approach as a combination of the two previous methods. However, the combination is not a simple addition of the two, but a process in which evaluators "need to understand the local context in substantial detail, such that the outcome reflects the process itself." While the final outcome of storytelling uses the information from capability design and issue list method, "it becomes new deal in the end." Thus, storytelling ultimately becomes a process of generating new projects.

\section{Propositions}

In summary, the patterns suggest four propositions that extend our orienting proposition that, as uncertainty and/or controversy increase, firms will increasingly evaluate potential deals via qualitative methods. The propositions help generalize understanding of how 
variation in two key types of socio-political processes, uncertainty and controversy, influences the types of qualitative methods that firms use for evaluating M\&A deals.

Proposition 1 (desktop valuation).The lower the uncertainty and controversy for an M\&A deal, the more likely a buyer will adopt desktop valuation methods.

Proposition 2 (capability design). The greater the uncertainty for an M\&A deal, while controversy remains low, the more likely a buyer will adopt capability design methods.

Proposition 3 (issue lists). The greater the controversy for an M\&A deal, while uncertainty remains low, the more likely a buyer will adopt issue list methods.

Proposition 4 (storytelling). The greater the controversy and uncertainty for an M\&A deal, the more likely a buyer will adopt storytelling methods.

\section{Conclusion}

This exploratory study identifies multiple forms of M\&A evaluation methods and helps identify boundary conditions in different explanations of M\&A evaluation. Our research design allows us to go beyond the basic idea of qualitative assessment and identify more precisely how variation in these two types of socio-political processes influences the types of qualitative methods that firms turn to. When uncertainty is high, capability design methods that attempt to come to grips with inability to specify simple distributions of potential outcomes are common. When controversy is high, issue list methods that attempt to identify and resolve differences among coalitions tend to arise. When both are high, storytelling is popular. Thus, the socio-political intensity of the methods tends to increase as both uncertainty and controversy rise, converging towards Bower (1970) and Bower and Gilbert's (2005) arguments concerning major investment decisions as a socio-political process. This convergence of boundaries helps resolve Bower's (2001: 92) concern that "we know surprisingly little about mergers and acquisitions, despite the buckets of ink spilled on the topic."

\section{Implications for understanding and using M\&A evaluation methods}

These results offer two core insights about M\&A evaluation. First, the heterogeneity that we observe in M\&A evaluation methodologies across firms is not random but instead partly reflects combinations of uncertainty and controversy. Second, these patterns offer a more general model of M\&A evaluation tools and the special cases of desktop valuation, capability design, issue list, and storytelling methods. Rather than being a dominant model, the desktop valuation model arises with one of the special cases. Elements of these insights arise both in practice and in the academic literature but have not been combined or validated empirically. We believe that this paper is the first to do so. The generality of this approach addresses concerns that financial economists sometimes under-emphasize the benefits of incorporating behavioral explanations in activities such as M\&A assessment (e.g., see Shiller 2017), while more organizationally focused scholars sometimes downplay the role of financial analysis in such decisions (e.g., Bower 1970; Christensen et al. 2011).

Hence, basic financial methods and the multiple forms of socio-political processes exist as complementary methods, suitable in different contexts. Our analysis highlights the point that M\&A valuation involves choosing not only a deal, but also choosing a method to evaluate the deal. In choosing valuation methods and deals, firms will tend to consider diverse interpretations of factors such as uncertainty and controversy. This 
offers multiple paths to determine how to accomplish the firm's goals, to compute the possible value of a deal or even to shape the goals as part of the evaluation process.

The results offer four additional implications concerning (1) sequences of basic financial and more qualitative methods, (2) the nature of deal value, (3) differences concerning who leads the evaluation process, and (4) M\&A practice. First, financial analysis arises in all four methods but in different sequences. In the desktop evaluation that is common when both uncertainty and controversy are low, financial analysis typically leads, potentially in combination with other methods such as scenario planning in support of the financial analysis (Markowitz, 1952), with the goal of determining the underlying value of a deal. Different firms might reach to different deal values in such desktop valuation cases, depending on their forecasts and assumptions, but there would be substantial convergence in the process.

In the other three approaches, financial analysis typically follows the more qualitative initial assessments. With capability design, following initially generated options, financial analysis helps design projects and assesses the reliability of the options. With issue lists, financial analysis helps build consensus around possible alternatives. With storytelling, financial analysis becomes part of the language of a broader debate, reinforcing stories rather than generating them. In these cases, using Trice et al. (1969: 2) terms, financial analysis serves a role as an organizational ceremonial, helping to construct the value of a deal in a way that reflects the particular context of the firm, based on its mix of capabilities, needs, and organizational characteristics.

Second, the logic of the sequence of evaluation methods offers intuition concerning the endogenous nature of deal value. In many cases, a potential deal does not exist a priori with an underlying value for which an analyst strives to discover cash flows and risks. Instead, deals, their cash flows, and relevant risks often emerge through the evaluation process. In capability-building cases, financial analysis helps take the results of scenario analysis and goal setting to construct deals with appropriate cash flows and risks, while helping avoid undesirable situations. In issue list cases, financial valuation functions as a communication, coordination, and negotiation device that helps subgroups build, compare, and debate about valuation models and business plans. With storytelling, financial valuation assists with constructing the value of a deal through social interaction, simulation, and learning. Thus, financial valuation and other methods often operate as complementary platforms that socially construct the value of a target. In doing so, the perceived value of a target will often depend on which valuation method is used.

The complementarity of qualitative and quantitative methods is intriguing in its own right, in addition to the impact on endogenous value. The existence of complementary is not especially surprising. By contrast, demonstrating that the nature of the complementarity reflects differences in uncertainty and controversy is a contribution of the work.

Third, the results highlight relevant differences concerning who leads the evaluation process, in terms of (a) functional skill sets and (b) use of external advisors to assist with deal evaluation. (a) As we noted in describing the cases, the choice of method has implications for the skill sets of the people who lead the assessments: investment banking for desktop valuation, consulting and MBA experience for capability design, legal experience for issue lists, and broader mixes of experts for storytelling. (b) The results offer insights concerning the use of external advisors. When both uncertainty and controversy are low, employing investment bankers and accounting firms is common, likely because they have 
extensive comparative knowledge of similar cases and therefore can provide efficient analysis. When uncertainty is high and controversy is low, consulting firms or university faculty are sometimes engaged to produce research reports, likely because they provide investigative help with considering aspects of the deal that are difficult to measure. When uncertainty is low and controversy is high, lawyers become more common, likely because they have skills in analyzing contentious issues and suggesting solutions; while internal legal staff may take the lead, firms sometimes hire external lawyers if the controversy arises from novel concerns. When both uncertainty and controversy are high, the role of in-house teams tends to dominate (with support from external advisors such as lawyers), likely because the complexity of the context requires nuanced understanding.

Fourth, the study has implications for M\&A practice. It is important for deal makers to recognize that M\&A evaluation is not simply about assessing a deal with exogenous formulae; instead, some tools can shape the perceived value of a target. In turn, firms can conduct M\&A valuation strategy in two ways: (a) understanding a limited set of evaluation skills and pursuing targets at a particular uncertainty-controversy profile that suits those skills, such as sticking to cases where desk top evaluation is appropriate or (b) developing more extensive valuation capabilities that allow a firm to seek a wider variety of types of targets by embracing a fuller set of evaluation models.

\section{Higher level implications}

We believe that the work is relevant for two audiences beyond the core studies of M\&A. First, we provide insights for scholars who typically do not engage with the idea of socio-political processes but are open to the idea that there are important boundary conditions to the frameworks such as NPV. Second, scholars who do regularly engage with the idea of socio-political processes will be informed about how social constructs such as uncertainty and controversy will shape particular types of decisions.

At a more general level, the variation in methods is relevant to the classic debate on essentialism versus social constructionism. In essentialism, there is an essence that fundamentally characterizes observable objects as the common element of a set of existing things, even if the essence itself is unobservable. Identifying such an essence is a goal of philosophers; Plato is the seminal thinker in this view. In social constructionism, rather than existing as an underlying essence, the meaning of objects emerges through social interaction. In this view, meaning is inseparable from social contexts (Berger and Luckmann 1966). Both essentialism and social constructionism arise in the context of M\&A evaluation, depending on the states of uncertainty and controversy.

\section{Limits and future research}

The study has five limits that provide routes for future research. First, while our in-depth case with one chaebol in one country can enrich our understanding about M\&A evaluation processes, future research could enlarge our findings and intuitions to other countries, sectors, and periods, providing greater generalizability. How differences might arise is uncertain. If the affiliates of a chaebol have greater independence than the operating units of a North American or European firm, it is possible that they exhibit greater variation in M\&A evaluation methods or, alternatively, they might exhibit less variation if family ties and other cultural factors have particularly strong imprint in Korea. 
Second, approaches treating uncertainty, controversy, and M\&A evaluation methods as continuous concepts would generate additional nuance. Third, small firms with limited acquisition activity may have different processes of M\&A evaluation than the large chaebol that we selected for this study, which regularly considers deals. Fourth, because we cannot directly discover the cognitive processes in the mind of managers, we used interviews and document analysis; the propositions need to be tested beyond our case studies; studies based on real time observation or even brain wave studies such as MRI would be useful. Fifth, it would be useful to examine other factors that might influence choice of evaluation methods, such as deal size, both alone and in combination with uncertainty and controversy.

The results have five additional implications for future research. First, research could examine whether the findings are generalizable in other types of financial decision-making, such as capital budgeting and venture funding. In such cases, uncertainty and controversy are likely to influence resource allocation decisions. As in M\&A evaluation, uncertainty will constrain basic financial methods (e.g., Bower 1970; Burgelman 1983). In parallel, controversy limits the ability to use simple decision-making rules (e.g., Cyert and March 1963).

Second, it would be useful to assess whether the choice of M\&A evaluation methods-whether alone or combined with uncertainty and controversy-affects acquisition completion and, in turn, post-acquisition performance. Relatedly, it would be valuable to determine whether uncertainty and/or controversy create failure or deal avoidance, in which firms may not begin to evaluate targets with high levels of either factor.

Third, we found that people with different backgrounds tended to specialize in different evaluation techniques, which future studies could investigate in greater detail. Laamanen and Wallin (2009), similarly, find that the profiles of board members affect the choice of firms. Dearborn and Simon (1958; updated in Beyer et al. 1997) develop similar arguments. These tendencies likely reflect a matching process in which firms match relevant evaluation skills with the context of a deal; it would be useful to assess whether evaluator background sometimes overrides the context in selecting evaluation methods.

Fourth, the results offer a base for continuing research about business groups. The focal firm is a chaebol in a major market. The firm in the study shares some characteristics with other chaebol in Korea as well as with business groups in many emerging markets. Such common characteristics include affiliations among legally independent firms that influence the strategies of the affiliates, analogous to multi-business firms. It would be useful to examine whether the chaebol's unique characteristics dominate the choice of evaluation methods or, instead, whether this range of M\&A techniques is common in other business groups.

Fifth, it would be useful to investigate the role of deal importance in greater depth, including any impact of deal size. We did not find substantive differences based on size. Nonetheless, because we selected deals that were important to the chaebol, differences might arise for deals with lower profiles.

Despite its limitations, this paper develops a more general model of M\&A valuation than existing studies and arguments. In doing so, we identify when and how M\&A evaluation methods deviate from basic desktop valuation models, proposing uncertainty and controversy as key boundary conditions for desktop valuation models and different forms of socio-political methods. In part, the results are case-specific, providing rich descriptions about M\&A evaluation practices at a Korean chaebol. Well beyond the cases and the national context, we believe that the results offer insights for M\&A evaluation in many settings. 


\section{Endnotes}

${ }^{1}$ As Knight (1921: 20) put it: “... a measurable uncertainty, or 'risk' proper, as we shall use the term, is so far different from an unmeasurable one that it is not in effect an uncertainty at all." Hence, Knightian uncertainty occurs when one cannot specify a reliable distribution. In parallel, scholars sometimes use the term "ambiguity" to mean qualitative (unmeasurable) uncertainty ("Knightian uncertainty"), as distinct from quantitative (measurable) uncertainties ("risk" in Knightian terms).

${ }^{2}$ Let us use a simple example of the four uncertainty-controversy combinations. Suppose there are two people and two ways to describe the probability distribution about the prospects of a deal. With low uncertainty and low controversy, both people believe and use a single probability distribution for the evaluation. With high uncertainty and low controversy, neither person knows which probability distribution to use. With high controversy and low uncertainty, both people believe the same distribution but have different objectives for the deal. With high uncertainty and high controversy, neither knows which distribution to use and the two have different opinions about possible outcomes. Although we treat uncertainty and controversy as binary variables, we recognize that the concepts are continuous. The high-low measurement keeps the number of cases and interviews manageable.

${ }^{3}$ During several initial interviews, we asked about recording but, in each case, the respondents firmly said no. Indeed, some managers did not feel comfortable even with our asking about recording. Hence, we stopped asking managers about recording because we did not want to make them defensive in response to our questions. The objections and discomfort may reflect the culture of Korean business. However, we suspect that it also would be difficult to record conversations about M\&A deals and their valuation in Europe or North America, both because the deals often are socially complex and because the financial (and career) stakes are often high..

\section{Appendix 1}

Conceptual arguments about why uncertainty and controversy are relevant for M\&As

Conceptual arguments about uncertainty and controversy that arise in several strategy and organizational literatures apply to factors that arise in the acquisition literature, such as relatedness $\mathrm{v}$. unrelatedness and cost v. revenue synergies.

\section{Relatedness and complementarity}

M\&As between strategically related firms can generate abnormal performance (Barney 1988). However, uncertainty and controversy can moderate the relationship, for two reasons. First, dynamic complementarities under uncertainty can affect M\&A. Furthermore, since dynamic complementarities within volatile environments can generate novel ways to configure and combine existing resource base, they can in turn define relatedness dynamically (Lien \& Klein 2006; Foss et al. 2007). The literature on dynamic capabilities and M\&A offers more general arguments (e.g., Helfat et al. 2009).

Second, relatedness and social relations jointly determine organizational linkages (Tsai 2000). National and cultural relatedness improves the value of M\&A significantly (Weber et al. 1996). Relatedness in the backgrounds of top management teams affects M\&A performance (Krishnan et al., 1997). In turn, conflict of interest has been an important variable in the finance and economics literature on M\&A (e.g. Jensen 1986). 


\section{Revenue synergy}

Contexts with high uncertainty often offer substantial potential new revenue, including synergies that build on a firm's existing resources, due to the upside of unknown opportunities. The need to garner new resources to attempt to take advantage of the opportunities creates incentives to use M\&A in contexts with substantial uncertainty (Han et al. 2012; Garriga et al. 2013). On the other hand, high uncertainty increases contracting costs, so that the postmerger integration process can fail to achieve either revenue or cost synergy (Mailath et al. 2004). Vaara (2003) offers related arguments concerning ambiguity.

Controversy can shape revenue synergy in M\&A. In order to generate revenue synergy, M\&A partners need to exert effort. However, the partners have incentives to free-ride on the other's efforts (Banal-Estañol \& Seldeslachts 2011). In practice, most M\&A deals generate financial goodwill on the balance sheet because acquiring companies need to pay premiums to the targets. In case of difficulty in expanding revenues through the expected sales increase, goodwill amortization costs may be higher than expected, which becomes the source of much ex post controversy that shapes attitudes about future deals.

\section{Cost synergy}

M\&A can achieve cost synergies by integrating redundant functions and teams. This typically results in both social conflict and uncertainty (Frensch 2007). Entrenchment strategies by managers influence the likelihood of divestiture (Fulghieri \& Hodrick 2006). M\&As intended to generate cost synergies especially affect human and cultural factors in organization, which in turn can explain why many takeovers fail (Cartwright et al. 1992; Cartwright \& Cooper 1993).

Cost synergy is also related with uncertainty. Basic synergy-based mergers can weaken firm capabilities to respond to an uncertain environment (Shaver 2006). Action interdependencies between teams create challenges in separating their contributions in order to reduce redundancies (Simon 1991).

The combination of cost synergy and conflict is a highly relevant practical concern. One of the main objectives for those who promote an M\&A is cost efficiency through economies of scale after the merger. However, conflicts can reduce this cost synergy significantly. For example, in the case of employee welfare and benefits, there is a downward rigidity in the form of sticky wages, so if there is a difference between the two companies, they are often adjusted based on the higher company standards or via layoffs, both of which can generate controversies.

\section{Appendix 2}

\section{Background information about chaebols Literal meaning of chaebol}

A chaebol is a collection of officially independent companies but under a single administrative and financial control of a family in Korea. Literally, chaebol means a group or clan of wealth. "Chae" means wealth or finance; "bol" means exclusive faction or clique. In Chinese characters, chaebol and zaibatsu (the pre-war Japanese business groups) are same.

\section{Legal meaning}

The Korea Fair Trade Commission (KFTC) defines a business group as a group of companies with more than $30 \%$ of shares owned by controlling shareholders and its affiliated companies. Each year, the KFTC ranks business groups on asset size. The top 30 of such business groups are often referred as chaebols in academic papers. 


\section{Historical background}

Chaebols have been the engine of the rapid economic growth in Korea ("the miracle of the Han river") and continue to account for a great percentage of the Korean economy. Korean military governments created and supported chaebols deliberately as a growth strategy, particularly following the military coup in 1961. In comparison, Japanese zaibatsu grew based on the procurement for military supplies in the 1930s. As they grew, both Korea chaebol and Japanese zaibatsu (and, in their post-war version, keiretsu) played important roles as capital providers to overcome limited external capital markets in the two countries.

\section{Ownership structure}

Professional managers run the day-to-day operations of the individual firms (subsidiaries) in a chaebol. However, ultimate control power rests with a chongsu, literally meaning a general head, and with key members of the founding family. These central office leaders can make the key corporate decisions for all subsidiaries based on cross-holding pyramidal ownership structure and inter-subsidiary transactions ("internal markets"). This centralized ownership structure allows speedy decision-making while often stirring controversies.

\section{Internal markets}

Member firms in a chaebol system commonly trade intermediate inputs with each other. The main member companies offer collateral and guarantees for payments and bank loans made to other members. The internal labor markets and internal capital markets are particularly important to exercise control power and so are under the constant supervision of the powerful central office.

\section{Central office and member firms (subsidiaries)}

The member firms of a chaebol are under the direct control of the group's central office, which is in turn controlled by the founding family. In this structure, the powerful central office is a de facto holding company. The central office strongly leads corporate governance, human resources, capital budgeting, and internal monitoring of all subsidiaries.

\section{Weak governance structure}

Founding families typically own a small equity stake of a chaebol but pyramidal, crossholding, and circular ownership allows the family to exercise immense control. The wedge between control (power) and ownership (cash flow right) can create multilateral agency problems between family members and other shareholders, such as tunneling resources out of the firm for the private benefit of family while sacrificing other investors.

\section{Comparison to the Japanese system}

Three differences are important. First, the Japanese system of zaibatsu and keiretsu is bank-centered. By contrast, the Korean government prevents a chaebol from owning banks, so that chaebols developed internal market transactions and tight government relationships. Second, chaebols are more hierarchical and centralized around a founding family than the Japanese system, partly reflecting their more recent history. Interestingly, the Korean system highlights blood relationships, while the Japanese focuses on family tradition in which adopted children or a son-in-law can carry on the tradition. Third, contrary to tight family control in chaebol, the Japanese system has greater separation of ownership and management, in part because a single family rarely controls a whole Japanese network. 


\section{Appendix 3}

The acquisition literature has identified several key factors that shape acquisition strategy, including relatedness $\mathrm{v}$. unrelatedness and cost v. revenue synergies. Such factors might co-vary with the factors we investigate, uncertainty and controversy. As the following table shows, though, our cases exhibit only mild heterogeneity on relatedness and the two types of synergy. This implies that variation in omitted variables has only limited correlation with independent variables in our sample, which in turn means that our interpretations about how evaluation methods differ based on variation in uncertainty and controversy should have only limited bias.

Table 4 Case characteristics other than uncertainty and controversy

\begin{tabular}{|c|c|c|c|}
\hline Deal targets & Relatedness & Revenue synergy & Cost synergy \\
\hline Portal & $\begin{array}{l}\text { Highly related; purchase of } \\
\text { search engine and Internet } \\
\text { capabilities by a portal }\end{array}$ & $\begin{array}{l}\text { Enhanced distribution channel } \\
\text { for the buyer's contents; pick } \\
\text { winners at early stage in } \\
\text { related sector }\end{array}$ & $\begin{array}{l}\text { Little; while some software } \\
\text { engineers are redundant }(+) \text {, } \\
\text { the firm saves search costs to } \\
\text { recruit further engineers by } \\
\text { relocating redundant ones }(-)\end{array}$ \\
\hline SmallEnergy & Highly related; same sector & $\begin{array}{l}\text { Reduce excess capacity in the } \\
\text { sector in order to increase } \\
\text { market power and stability }\end{array}$ & $\begin{array}{l}\text { Little; the facility of the target is } \\
\text { less advanced than that of the } \\
\text { buyer }\end{array}$ \\
\hline BigMedia & $\begin{array}{l}\text { Moderately related; exploit the } \\
\text { trend of media-communication } \\
\text { convergence }\end{array}$ & $\begin{array}{l}\text { Enhanced distribution channel } \\
\text { for the buyer's contents }\end{array}$ & Little overlap in cost structure \\
\hline BigEnergy & $\begin{array}{l}\text { Moderately related; same sector } \\
\text { but different location }\end{array}$ & $\begin{array}{l}\text { Vertical integration increases } \\
\text { the market power of the } \\
\text { buyer }\end{array}$ & $\begin{array}{l}\text { Little; economies of scale are } \\
\text { difficult because of } \\
\text { geographical factors and } \\
\text { different position in value chain }\end{array}$ \\
\hline Chip & $\begin{array}{l}\text { Moderately related; use } \\
\text { consumer intelligence gained } \\
\text { in telecom service to develop } \\
\text { non-memory chips; exploit the } \\
\text { trend of software-hardware } \\
\text { convergence }\end{array}$ & $\begin{array}{l}\text { Help target with the chaebol's } \\
\text { internal resources; transfer the } \\
\text { target's capability to the } \\
\text { buyer's businesses }\end{array}$ & $\begin{array}{l}\text { Little overlap between service } \\
\text { (buyer) and manufacturing } \\
\text { (target) value chain }\end{array}$ \\
\hline Apparel & $\begin{array}{l}\text { Related; the buyer has traded } \\
\text { clothing and extended its } \\
\text { business with the M\&A }\end{array}$ & $\begin{array}{l}\text { Design capability of the target } \\
\text { is important to upgrade } \\
\text { clothing business of the buyer }\end{array}$ & $\begin{array}{l}\text { No cost synergy because the } \\
\text { buyer and the seller are in } \\
\text { different segments of value } \\
\text { chain }\end{array}$ \\
\hline SNS & $\begin{array}{l}\text { Related; early social network } \\
\text { service (seller); Internet affiliate } \\
\text { (buyer) }\end{array}$ & $\begin{array}{l}\text { Having both social network } \\
\text { service and search engine can } \\
\text { increase user base much }\end{array}$ & $\begin{array}{l}\text { Moderate cost synergy; can } \\
\text { save ad expenses, but the } \\
\text { businesses of buyer and seller } \\
\text { so far have no specific overlap }\end{array}$ \\
\hline Card & $\begin{array}{l}\text { Moderately related; credit card } \\
\text { business (seller) has been an } \\
\text { important target of many } \\
\text { communication firm (buyer); } \\
\text { fintech offers similar recent } \\
\text { experience }\end{array}$ & $\begin{array}{l}\text { Customer data of the buyer } \\
\text { and the seller can be } \\
\text { combined; mobile services } \\
\text { can include finance function }\end{array}$ & $\begin{array}{l}\text { No clear cost synergy between } \\
\text { finance and } \\
\text { telecommunication; marketing } \\
\text { can be more efficient by } \\
\text { combining customer data, but } \\
\text { the buyer increased marketing } \\
\text { expenses after the merger }\end{array}$ \\
\hline BigMobile & $\begin{array}{l}\text { Highly related; major US } \\
\text { wireless operator (seller); } \\
\text { telecom affiliate (buyer) }\end{array}$ & $\begin{array}{l}\text { Moderate revenue synergy } \\
\text { because of geographic } \\
\text { differences although the } \\
\text { buyer and the seller are in the } \\
\text { same sector }\end{array}$ & $\begin{array}{l}\text { No cost synergy in the short } \\
\text { run because the buyer cannot } \\
\text { restructure the seller due to } \\
\text { stakeholders }\end{array}$ \\
\hline SmallMedia & $\begin{array}{l}\text { Moderately related; media } \\
\text { content (seller) has been an } \\
\text { important target of many } \\
\text { communication firms (buyer); } \\
\text { digital convergence is relevant }\end{array}$ & $\begin{array}{l}\text { The buyer can sell the } \\
\text { contents of the seller through } \\
\text { its mobile channels }\end{array}$ & $\begin{array}{l}\text { No cost synergy because of } \\
\text { the differences in culture, } \\
\text { value chain, and size. }\end{array}$ \\
\hline
\end{tabular}




\section{Appendix 4}

Table $\mathbf{5}$ Table desktop valuation tools

\begin{tabular}{|c|c|c|}
\hline Desktop valuation tool & Characteristics & Challenges \\
\hline Comparables & $\begin{array}{l}\text { This technique assesses a target in } \\
\text { comparison to a similar asset. It is a } \\
\text { special case of comparative valuation. }\end{array}$ & It is difficult to find comparable cases. \\
\hline Historical analysis & $\begin{array}{l}\text { This technique evaluates a deal } \\
\text { based on similar deals and valuation } \\
\text { in the past transactions. }\end{array}$ & $\begin{array}{l}\text { Diverse business environments and } \\
\text { deal-specific information can make } \\
\text { comparisons impractical. Past comparison } \\
\text { deals may be underpaid or overpaid. }\end{array}$ \\
\hline Present values & $\begin{array}{l}\text { This technique estimates the present } \\
\text { value of future cash flows. }\end{array}$ & $\begin{array}{l}\text { Results are sensitive to terminal values } \\
\text { and discount rates. }\end{array}$ \\
\hline Sum of the parts analysis & $\begin{array}{l}\text { This technique evaluates a firm by } \\
\text { division, combining diverse valuation } \\
\text { techniques. }\end{array}$ & $\begin{array}{l}\text { It can be difficult to compare firms } \\
\text { with different basis for diversification. }\end{array}$ \\
\hline Leveraged buyout analysis & $\begin{array}{l}\text { This technique assumes high leverage } \\
\text { in a deal and requires } 25 \sim 35 \% \text { of } \\
\text { internal rate of return over } 3 \sim 5 \text { years. }\end{array}$ & $\begin{array}{l}\text { This method is sensitive to the timing } \\
\text { of acquisition and resale. }\end{array}$ \\
\hline
\end{tabular}

\section{Abbreviations}

CEO: Chief executive officer; CSP: Corporate strategy and planning team; EBITDA: Earnings before interest, taxes, depreciation, and amortization; IRR: Internal rate of return; LBO: Leveraged buyout; M\&A: Mergers and acquisitions; NPV: Net present value; SNS: Social network service

\section{Acknowledgements}

We wish to express a sincere thank you to the men and women who graciously agreed to participate in interviews. We thank the editor and two anonymous reviewers for their constructive comments, which helped us to improve the manuscript.

\section{Availability of data and materials}

We cannot disclose any information that can reveal the identity of acquirers and targets. We can supply other materials upon request.

\section{Authors' contributions}

RB, WM, and HGK conceived of the presented idea. HGK and WW designed and performed the interviews and qualitative analysis. WM and HGK developed the theory and verified the analytical methods. RB and WM supervised the findings of this work. All authors discussed the results and contributed to the final manuscript. WM is the corresponding author. All authors read and approved the final manuscript.

\section{Funding \\ None}

\section{Competing interests}

The authors declare that they have no competing interests.

\section{Publisher's Note}

Springer Nature remains neutral with regard to jurisdictional claims in published maps and institutional affiliations.

\section{Author details}

${ }^{1}$ School of Business, Hanyang University, Seoul, Republic of Korea. ${ }^{2}$ Ewha Womans University, Seoul, Republic of Korea. ${ }^{3}$ The Fuqua School of Business, Duke University, Durham, NC, USA. ${ }^{4}$ Strategic Management, Rotman School of Management, Toronto, Canada.

Received: 1 December 2016 Accepted: 27 November 2017

Published online: 15 January 2018

\section{References}

Agarwal R, Anand J, Bercovitz J, Croson R (2012) Spillovers across organizational architectures: the role of prior resource allocation and communication in post-acquisition coordination outcomes. Strateg Manag J 33:710-733

Agrawal A, Jaffe J (2000) The post merger performance puzzle. Advances in Mergers and Acquisitions 1:119-156 Akerlof GA (1970) The market for lemons: quality uncertainty and the market mechanism. Q J Econ 84(3):488-500 Banal-Estanol A, Seldeslachts J (2011) Merger failures. Journal of Economics \& Management Strategy 20(2):589-624 Barney JB (1988) Returns to bidding firms in mergers and acquisitions: Reconsidering the relatedness hypothesis. Strateg Manag J 9(S1):71-78 
Berger PL, Luckmann T (1966) The social construction of reality: a treatise in the sociology of knowledge (no. 10). Penguin, UK

Berry H (2006) Shareholder valuation of foreign investment and expansion. Strateg Manag J 27(12):1123-1140

Bettis RA, Gambardella A, Helfat C, Mitchell W (2015) Qualitative empirical research in strategic management. Strateg Manag J 36(5):637-639

Beyer JM, Chattopadhyay P, George E, Glick WH, Ogilvie DT, Pugliese D (1997) The selective perception of managers revisited. Acad Manag J 40(3):716-737

Boudreaux DJ, Holcombe RG (1989) The Coasian and Knightian theories of the firm. Manag Decis Econ 10(2):147-154

Bower JL (1970) Managing the resource allocation process: a study of corporate planning and investment. Harvard Business School Press, Boston

Bower JL (2001) Not all M\&As are alike and that matters. Harv Bus Rev 79(3):92-101

Bower JL, Gilbert CG (2005) From resource allocation to strategy. Oxford University Press, Oxford

Brealey RA, Myers SC, Allen F (2005) Principles of corporate finance. McGraw-Hill/lrwin, New York

Burgelman RA (1983) A process model of internal corporate venturing in the diversified major firm. Adm Sci Q 28(2): 223-244

Burton RM, Obel B, Håkonsson D (2015) Organizational design: a step-by-step approach. Cambridge University Press, Cambridge

Caballero RJ, Krishnamurthy A (2008) Collective risk management in a flight to quality episode. J Financ 63(5):2195-2230

Capron L (1999) The long-term performance of horizontal acquisitions. Strateg Manag J 20:987-1018

Capron L, Dussage P, Mitchell W (1998) Resource redeployment following horizontal mergers and acquisitions in Europe and North America, 1988-1992. Strateg Manag J 19(7):631-661

Cartwright S, Cartwright S, Cooper CL (1992) Mergers and acquisitions: the human factor. Butterworth-Heinemann, Oxford

Cartwright S, Cooper CL (1993) The role of culture compatibility in successful organizational marriage. Acad Manag Exec 7(2):57-70

Chang SJ (2003) Financial crisis and transformation of Korean business groups: the rise and fall of chaebols. Cambridge University Press, Cambridge

Christensen CM, Alton R, Rising C, Waldeck W (2011) The new M\&A playbook. Harv Bus Rev 89(3):48-57

Coase RH (1946) The marginal cost of controversy. Economica 13(51):169-182

Coff R (1999) How buyers cope with uncertainty when acquiring firms in knowledge-intensive industries: caveat emptor. Organ Sci 10(2):144-161

Cohen BD, Dean TJ (2005) Information asymmetry and investor valuation of IPOs: top management team legitimacy as a capital market signal. Strateg Manag J 26:683-690

Cyert RM, March JG (1963) A behavioral theory of the firm. Blackwell, New York

Dearborn DC, Simon HA (1958) Selective perception: a note on the departmental identifications of executives. Sociometry 21(2):140-144

Eisenhardt KM (1989) Building theories from case study research. Acad Manag Rev 14(4):532-550

Eisenhardt KM, Zbaracki MJ (1992) Strategic decision making. Strateg Manag J 13(S2):17-37

Eisenmann TR, Bower JL (2000) The entrepreneurial M-form: strategic integration in global media firms. Organ Sci 11(3):348-355

Epstein LE (2001) Sharing ambiguity. Am Econ Rev 91(2):45-50

Foss K, Foss NJ, Klein PG, Klein SK (2007) The entrepreneurial organization of heterogeneous capital. J Manag Stud 44(7):1165-1186

Frensch, F. (2007). The social side of mergers and acquisitions: cooperation relationships after mergers and acquisitions. Springer Science \& Business Media

Fulghieri P, Hodrick LS (2006) Synergies and internal agency conflicts: the double-edged sword of mergers. Journal of Economics \& Management Strategy 15(3):549-576

Garriga H, Von Krogh G, Spaeth S (2013) How constraints and knowledge impact open innovation. Strateg Manag J 34(9):1134-1144

Gaughan PA (2002) Mergers, acquisitions, and corporate restructurings. Wiley, New York

Giddens A (1979) Central problems in social theory. University of California Press, Berkeley

Giddens A (1984) The constitution of society: outline of the theory of structuration. University of California Press, Berkeley

Gilboa I, Schmeidler D (1989) Maxmin expected utility with non-unique prior. J Math Econ 18(2):141-153

Graham JR, Harvey CR (2002) How do CFOs make capital budgeting and capital structure decisions? Journal of Applied Corporate Finance 15(1):8-23

Graham JR, Harvey CR, Rajgopal S (2005) The economic implications of corporate financial reporting. J Account Econ 40(1):3-73

Han K, Oh W, Im KS, Oh H, Pinsonneault A, Chang RM (2012) Value creation and wealth spillover in open innovation alliances. MIS Q 36(1):291-316

Hasan I, Kobeissi N, Wang H (2011) Global equity offerings, corporate valuation, and subsequent international diversification. Strateg Manag J 32(7):787-796

Haspeslagh PC, Jemison DB (1991) Managing acquisitions: creating value through corporate renewal. Free Press, New York

Helfat CE, Finkelstein S, Mitchell W, Peteraf M, Singh H, Teece D, Winter SG (2009) Dynamic capabilities: understanding strategic change in organizations. Wiley

Higgins MC, Gulati R (2006) Stacking the deck: the effects of top management backgrounds on investor decisions. Strateg Manag J 27:1-25

Hobbes, T. (1651) Leviathan (The Project Gutenberg EBook of Leviathan, 2002). http://www.gutenberg.org/etext/3207

Holmstrom B, Kaplan SN (2001) Corporate governance and merger activity in the United States: making sense of the 1980s and 1990s. J Econ Perspect 15:121-144

Holmstrom, B., Tirole, J. (1989) The theory of the firm. In: Schmalensee R, Willig RD (eds) Handbook of industrial organization, North Holland, pp 61-133 
Huber GP, Power DJ (1985) Retrospective reports of strategic-level managers: guidelines for increasing their accuracy. Strateg Manag J 6(2):171-180

Jensen MC (1986) Agency costs of free cash flow, corporate finance, and takeovers. Am Econ Rev 76(2):323-329

Jensen MC, Meckling WH (1976) Theory of the firm: managerial behavior, agency costs, and ownership structure. J

Financ Econ 3(4):305-360

Kaplan S (2008) Framing contests: strategy making under uncertainty. Organ Sci 19(5):729-752

Keynes JM (1921) Treaties on probability. MacMillan, London

Knight FH (1921) Risk, uncertainty and profit. Houghton Mifflin, Boston

Koller T, Goedhart M, Wessels D (2010) Valuation: measuring and managing the value of companies. Wiley, New York Krishnan, H. A., Miller, A., \& Judge, W. Q. (1997). Diversification and top management team complementarity: is performance improved by merging similar or dissimilar teams? Strategic management journal, 361-374

Laamanen T (2007) On the role of acquisition premium in acquisition research. Strateg Manag J 28:1359-1369

Laamanen T, Keil T (2008) Performance of serial acquirers: toward an acquisition program perspective. Strateg Manag J 29(6):663-672

Laamanen T, Wallin J (2009) Cognitive dynamics of capability development paths. J Manag Stud 46(6):950-981

Levitt B, March JG (1988) Organizational learning. Annu Rev Sociol 14:319-340

Lien LB, Klein PG (2006) Relatedness and acquirer performance. In: Advances in mergers and acquisitions, pp 9-23 Emerald Group Publishing Limited

Mailath GJ, Nocke V, Postlewaite A (2004) Business strategy, human capital, and managerial incentives. Journal of Economics \& Management Strategy 13(4):617-633

March JG (1991) Exploration and exploitation in organizational learning. Organ Sci 2(1):71-87

Maritan CA (2001) Capital investment as investing in organizational capabilities: an empirically grounded process model. Acad Manag J 44(3):513-531

Markowitz H (1952) Portfolio selection. J Financ 7:77-91

Mellen CM, Evans FC (2010) Valuation for M\&A: building value in private companies, 2nd edn. Wiley, New York Muehlfeld K, Rao Sahib P, Van Witteloostuijn A (2012) A contextual theory of organizational learning from failures and successes: a study of acquisition completion in the global newspaper industry, 1981-2008. Strateg Manag J 33:938-964 Narayanan MP (1985) Managerial incentives for short-term results. J Financ 15(1):1469-1484

Nelson RR, Winter SG (1982) An evolutionary theory of economic change. Harvard University Press, Cambridge Nishimura KG, Ozaki H (2006) Irreversible investment and Knightian uncertainty. J Econ Theory 136(1):668-694 Nutt PC (1998) Framing strategic decisions. Organ Sci 9(2):195-216

Pettigrew A (1973) The politics of organizational decision making. Tavistock, London

Rawls J (1971) A theory of justice. New York, Belknap

Ross SA, Westerfield RW, Jaffe J (2009) Corporate finance. McGraw-Hill, New York

Sanders WG, Boivie S (2004) Sorting things out: valuation of new firms in uncertain markets. Strateg Manag J 25(2):167-186

Schmeidler D (1989) Subjective probability and expected utility without additivity. Econometrica 57(3):571-587

Shane S (2000) Prior knowledge and the discovery of entrepreneurial opportunities. Organ Sci 11(4):448-469

Shaver JM (2006) A paradox of synergy: contagion and capacity effects in mergers and acquisitions. Acad Manag Rev 31(4):962-976

Shiller, R.J. (2017) Another Nobel surprise for economics. Project Syndicate (October 10, 2017). https://www.projectsyndicate.org/commentary/richard-thaler-nobel-behavioral-economics-by-robert-j-shiller-2017-10?utm_source= Project+Syndicate+Newsletter\&utm_campaign=724ae23045-sunday_newsletter_15_10_2017\&utm_medium= email\&utm_term=0_73bad5b7d8-724ae23045-93648981

Simon HA (1991) Organizations and markets. J Econ Perspect 5(2):25-44

Stirling A (2010) Keep it complex. Nature 468:1029-1031

Strauss AL, Corbin JM (1990) Basics of qualitative research: techniques and procedures for developing grounded theory. Sage Publications, New York

Tjosvold D (1985) Implications of controversy research for management. J Manag 11(3):21-37

Tjosvold D, Deborah D (1980) Effects of controversy within a cooperative or competitive context on organizational decision making. J Appl Psychol 65(5):590-595

Trautwein F (1990) Merger motives and merger prescriptions. Strateg Manag J 11(4):283-295

Trice HM, Belasco J, Alutto JA (1969) The role of ceremonials in organizational behavior. Ind Labor Relat Rev 23(1):40-51

Tsai W (2000) Social capital, strategic relatedness and the formation of intraorganizational linkages. Strateg Manag J: 925-939

Uhlaner R, West A (2011) McKinsey global survey results: organizing for M\&A. McKinsey Quarterly December:1-8

Uhlenbruck K, Hitt MA, Semadeni M (2006) Market value effects of acquisitions involving internet firms: a resourcebased analysis. Strateg Manag J 27(10):899-913

Vaara E (2003) Post-acquisition integration as sensemaking: glimpses of ambiguity, confusion, hypocrisy, and politicization. J Manag Stud 40(4):859-894

Wall JA, Callister RR (1995) Conflict and its management. J Manag 21(3):515-558

Weber Y, Shenkar O, Raveh A (1996) National and corporate cultural fit in mergers/acquisitions: an exploratory study. Manag Sci 42(8):1215-1227

Weick KE (1979) The social psychology of organizing, 2nd edn. McGraw-Hill, New York

Williamson OE (1975) Markets and hierarchies: analysis and antitrust implications: a study in the economics of internal organization. Free Press, New York

Wood MS, McKinley W (2010) The production of entrepreneurial opportunity: a constructivist perspective. Strateg Entrep J 4(1):66-84

Yin R (1985) Case study research. Sage Publications, Beverly Hills

Zimmerman MA, Zeitz GJ (2002) Beyond survival: achieving new venture growth by building legitimacy. Acad Manag $\operatorname{Rev} 27(3): 414-431$ 